\title{
Estradiol and luteinizing hormone reverse memory loss in phencyclidine model of schizophrenia: Evidence for hippocampal GABA action
}

Alexander J. Riordan*, Ari W. Schaler, Jackson B. Fried, Tracie A. Paine, Janice E. Thornton

Oberlin College Neuroscience Department 119 Woodland St, Oberlin OH 44074, USA

Running title: Hormonal rescue of memory in schizophrenia model

Keywords: schizophrenia, estrogen, luteinizing hormone, GABA, recognition memory, hippocampus

\section{${ }^{*}$ Corresponding author:}

Alexander J. Riordan

Princeton Neuroscience Institute

Princeton University

Washington Road, Princeton, NJ 08544

ariordan@princeton.edu

Tel: N/A

Fax: N/A 
Riordan 2

\section{ABSTRACT}

The cognitive symptoms of schizophrenia are poorly understood and difficult to treat. Estrogens may mitigate these symptoms via unknown mechanisms. To examine these mechanisms, we tested whether increasing estradiol $(E)$ or decreasing luteinizing hormone $(\mathrm{LH})$ could rescue declarative memory in a phencyclidine (PCP) model of schizophrenia. We then assessed whether changes in cortical or hippocampal GABA may underlie these effects. Female rats were ovariectomized and injected subchronically with PCP. To modulate $\mathrm{E}$ and $\mathrm{LH}$, animals received hormone capsules or Antide injections. Short-term episodic memory was assessed using the novel object recognition task. Brain expression of GAD67 was analyzed via western blot, and parvalbumincontaining cells were counted using immunohistochemistry. Some rats received hippocampal infusions of a $\mathrm{GABA}_{A}$ agonist, $\mathrm{GABA}_{A}$ antagonist, or GAD inhibitor before behavioral testing. We found that PCP reduced hippocampal GAD67 and abolished object recognition. Antide restored hippocampal GAD67 and rescued recognition memory in PCP-treated animals. Estradiol reversed PCP's amnesic effect but failed to restore hippocampal GAD67. PCP did not cause significant differences in number of parvalbumin-expressing cells or cortical expression of GAD67. Hippocampal infusions of a $\mathrm{GABA}_{\mathrm{A}}$ agonist restored memory in PCP-treated rats. Blocking hippocampal GAD or $\mathrm{GABA}_{\mathrm{A}}$ receptors in ovx animals reproduced memory loss similar to PCP and inhibited estradiol's memory rescue in PCP-treated animals. In summary, decreasing LH or increasing E can reverse memory loss in a PCP model of schizophrenia. Alterations in hippocampal GABA may contribute to both PCP's effects on declarative memory and the hormones' ability to reverse them. 


\section{INTRODUCTION}

Schizophrenia is a common neuropsychiatric disorder that causes devastating cognitive, negative, and positive symptoms (McGrath et al. 2008). Despite the importance of cognitive symptoms for a patient's long-term well-being, current treatments for schizophrenia fail to adequately improve them (Green et al. 2004). Better therapies and a greater understanding of the brain mechanisms underlying cognitive loss in schizophrenia are needed.

A dominant model of schizophrenia suggests that hypofunctioning N-methyl-daspartate glutamate receptors (NMDARs) play a role in generating schizophrenia symptoms (Moghaddam and Javitt 2012). Repeated exposure to NMDAR antagonists causes schizophrenia-like symptoms in healthy humans and exacerbates symptoms in those with schizophrenia (Jones et al. 2011; Moghaddam and Javitt 2012; Nakazawa et al. 2012) . Based on these findings, animal models of schizophrenia using repeated (sub-chronic) treatment with NMDAR antagonists such as phencydlidine (PCP) and ketamine have been developed (Jones et al. 2011; Moghaddam and Javitt 2012). Animals in a number of species that have been subjected to these regimens show traits that approximate positive, negative, and cognitive symptoms of schizophrenia, including loss of short-term episodic memory (Jones et al. 2011; Rajagopal et al. 2014). Although no animal model perfectly replicates schizophrenia, the unique cross-species validity of NMDAR antagonist models has rendered them enduring tools for studying possible mechanisms and treatments for the disorder (Jones et al. 2011).

Current theories propose that NMDA hypofunction disrupts gamma-amino-butyricacid (GABA) neurons, causing cognitive loss in schizophrenia (Lewis et al. 2012). Experiments suggest that abnormal GABA-containing inhibitory neurons are common in schizophrenia (Nakazawa et al. 2012). Post-mortem analyses reveal that the brains of people with schizophrenia express lower amounts of the rate-limiting enzyme for GABA 
synthesis, glutamic acid decarboxylase 67 (GAD67) (Benes et al. 2007; Lewis et al. 2012). There is also reduced expression of calcium-binding protein parvalbumin (PV), which marks a subset of GABAergic neurons (Beasley and Reynolds 1997; Zhang and Reynolds 2002). These GABAergic abnormalities are found in a number of brain regions thought to be important for declarative and short-term memory, including the hippocampus and frontal neocortex (Benes et al. 2007; Lewis et al. 2012; Zhang and Reynolds 2002). Studies in NMDAR animal models of schizophrenia have found similar deficits of GAD67 and PV expression in the prelimbic cortex and hippocampus, further supporting their possible mechanistic role in schizophrenia-like cognitive loss (AbdulMonim et al. 2007; Behrens et al. 2007; Kaalund et al. 2013).

There are indications that estradiol can mitigate cognitive symptoms in schizophrenia and animal models of the disease (for review see McGregor et al. 2017). Clinical trials have suggested that estrogen and analogues may improve some measures of cognition in males and females with schizophrenia (McGregor et al. 2017). Estradiol can also improve recognition memory in the PCP model of schizophrenia when given before or after PCP treatment (Roseman et al. 2012; Sutcliffe et al. 2008). Still, the underlying mechanisms of estradiol's cognitive rescue remain unknown, and the possibility that estradiol works through GABAergic pathways to restore memory has not been investigated.

Estrogen inhibits release of luteinizing hormone ( $\mathrm{LH}$ ) through negative feedback (Charlton 2008; Wise and Ratner 1980), and it is conceivable that estrogen's beneficial effects in schizophrenia are due to LH inhibition. High LH levels are associated with memory decline in humans, and rodent studies support a causal relationship (Burnham et al. 2016; Burnham and Thornton 2015; Casadesus et al. 2007). Nevertheless the molecular mechanisms underlying LH's amnesic effects remain uncharacterized, and the therapeutic possibilities of LH inhibition in schizophrenia are unknown. 
Here we tested whether modulating estradiol $(E)$ or $\mathrm{LH}$ could rescue recognition memory in the PCP model of schizophrenia, and if these hormones act by counteracting PCP's putative effects on GABA neurons. To examine the actions of $E$ and $L H$ without the confounds of hormonal cycles, we ovariectomized female rats and systematically altered their estradiol or LH levels (Roseman et al. 2012; Wise and Ratner 1980; Ziegler and Thornton 2010). We then injected them with subchronic PCP and assessed the rats' short-term recognition memory using the novel object recognition task (NORT) (Janhunen et al. 2015; Jones et al. 2011; Rajagopal et al. 2014; Roseman et al. 2012). NORT is widely used to assess episodic memory loss in animal models of schizophrenia, and performance in the task depends on specific functioning of cortical and hippocampal regions altered in the disorder (Benes et al. 2007; Broadbent et al. 2004; Cohen et al. 2013; Lewis et al. 2012; Oliveira et al. 2010; Rajagopal et al. 2014; Zhang and Reynolds 2002). When paired with a short intertrial interval, NORT also measures short-term memory, which is disrupted in humans with schizophrenia but improved by estrogenic compounds (McGregor et al. 2017; Rajagopal et al. 2014).

After these initial behavioral characterizations, we assessed whether the hormonal memory rescue may rely on GABAergic mechanisms. We first tested whether PCP reduced expression of GAD67 and PV in the dorsal hippocampus or prelimbic cortex and determined if our hormonal treatments restored these GABAergic markers. To assess whether changes in hippocampal GABA could account for PCP's disruption of recognition memory and the hormones' mnemonic rescue, respectively, we infused a $\mathrm{GABA}_{\mathrm{A}}$ receptor agonist into the dorsal hippocampus of PCP-treated females and blocked hippocampal $\mathrm{GABA}_{\mathrm{A}}$ receptors or GABA synthesis in non-PCP-treated controls and estradiol-treated PCP animals during NORT. 


\section{Riordan 6}

\section{MATERIALS AND METHODS}

\subsection{Subjects}

Adult female Sprague-Dawley rats (Hilltop Lab Animals, Inc., Scottdale, PA), 3-7 months old, were housed in groups of 2-3 in plastic cages (see supplementary methods). All procedures met NIH standards (National Research Council of the National Academies 2011) and were approved by the Oberlin College Institutional Animal Care and Use Committee.

\subsection{Ovariectomy, Hormones, and PCP treatment}

To control E levels, females were ovariectomized (ovx) under isoflurane anesthesia (1-3\% with $1 \mathrm{~L} / \mathrm{min} \mathrm{O}_{2}$ ) and implanted subcutaneously with either a silastic capsule filled with $17 \beta$-estradiol $(E)$ or a blank (Blk) capsule. Because of negative feedback between $\mathrm{E}$ and $\mathrm{LH}$, blank implants result in low $\mathrm{E}$ and high $\mathrm{LH}$, whereas $\mathrm{E}$ implants of this size result in physiological levels of E and low LH (Roseman et al. 2012; Wise and Ratner 1980; Ziegler and Thornton 2010). After surgery, animals were allowed to recover for $7 \mathrm{~d}$.

To create an animal model of schizophrenia, females were injected bidaily, IP with either PCP $(2 \mathrm{mg} / \mathrm{ml} / \mathrm{kg}$ ) or vehicle (sterile $0.9 \% \mathrm{NaCl} 1 \mathrm{ml} / \mathrm{kg}$ ) for $7 \mathrm{~d}$. Injections were followed by a $7 \mathrm{~d}$ washout period, during which all animals were handled (Roseman et al. 2012).

To lower LH levels in Blk animals, Antide (Ant: $1 \mathrm{mg} / \mathrm{ml} / \mathrm{kg})$ or vehicle $(1 \mathrm{ml} / \mathrm{kg}$ sterile $\mathrm{H}_{2} \mathrm{O}$ ) was injected sub-cutaneously $6 \mathrm{~h}$ before behavioral testing or sacrifice (Ziegler and Thornton 2010).

\subsection{Novel Object Recognition Test (NORT) and Locomotion Test}

Before testing, animals were habituated to the open field testing arena (supplementary methods). Animals then underwent novel object recognition testing as described elsewhere (Roseman et al. 2012). Object placement and type were 
counterbalanced to control for possible spatial or object preferences. Behavioral data were averaged for each female. Testers were blind to treatment group.

Exposure and test trial data are expressed as number of seconds animals explored each object. Test trial data are also expressed as a discrimination index $d$, where $d=$ (time novel object explored - time known object explored)/(time novel object explored + time known object explored). Any test in which an animal did not explore both objects was excluded.

To assess possible drug and hormone effects on locomotion, animals were placed individually into an open field box, and the number of lines crossed during a $5 \mathrm{~min}$ period was counted (see supplement) (Roseman et al. 2012).

\subsection{Western Blot}

Protein concentrations of GAD67 were measured in dorsal hippocampus and prelimbic cortex via western blot (Paxinos and Watson 2007) (see supplement for details). Briefly, animals were anaesthetized, decapitated, and brains were snap frozen in dry-ice-cooled isopentane (Sigma). Tissue punches from dorsal hippocampus and prelimbic cortex were sonicated, diluted to equal protein concentrations, and stored at $70^{\circ} \mathrm{C}$ until SDS-PAGE and transfer to nitrocellulose membranes. After blocking, membranes were incubated in mouse-anti-GAD67 antibody (Sigma, 1:2000), washed, then incubated in HRP-conjugated secondary antibody (Vector Labs, 1:5000). Membranes were exposed to chemiluminescent detection reagents (Thermo Fisher Scientific) and imaged. Membranes were stripped and re-probed for actin (Sigma, $1: 10000)$ using the same procedure.

Densitometry was performed for all sample bands using ImageJ. To control for sample loading or transfer differences, all GAD67 values were normalized over actin levels and intra-gel Blk controls. Three technical replicates were performed for hippocampal samples, and the median value was used as the final fold value for each 
animal. Outliers were determined using non-biased methods described in Leys et al., 2013 (see supplement) (Leys et al. 2013).

\subsection{Immunohistochemistry \& Cell Counting}

Rats were anesthetized and perfused, $50 \mu \mathrm{m}$ coronal brain sections were cut, and every fifth section was blocked then incubated in polyclonal rabbit-anti-parvalbumin antibody (Swant PV-28; 1:5000 in PBS) for $48 \mathrm{~h}$ at $4^{\circ} \mathrm{C}$. Sections were subsequently washed and incubated in biotinylated secondary antibody (goat-anti-rabbit IgG: 1:200, Vector Labs) for $45 \mathrm{~min}$ at RT. After further washes, sections were incubated in avidinbiotin-complex reagent for $1 \mathrm{~h}$ at RT and developed with diaminobenzidine. Sections were mounted, dehydrated, and cleared in a series of alcohol washes and histoclear, then coverslipped. Number of PV cells in prelimbic cortex, dentate gyrus, CA1, and CA3 regions of the hippocampus was counted at 100x by two independent raters. Inter-rater reliability was $95 \%$ and raters were blind to treatment group.

\subsection{Cannulae and Hippocampal Drug Infusions}

See supplement. Briefly, rats were anesthetized, and bilateral guide cannulae were implanted into dorsal hippocampus. Animals were allowed to recover for $5 \mathrm{~d}$.

Drugs were infused for $2 \mathrm{~min}$ at a rate of $0.25 \mu \mathrm{l} / \mathrm{min} / \mathrm{side}$ via infusion cannulae (1.5mm projection) using a microliter syringe and pump (KD Scientific). Infusers were kept in place for $2 \mathrm{~min}$ after infusion was complete (Burnham et al. 2016).

\subsection{Experimental Designs (see Fig 1A)}

\subsubsection{Expt 1. Effect of estradiol and Antide on PCP-induced memory loss}

Rats were ovariectomized, implanted with Blk or E capsules, then treated with the PCP or vehicle (veh) regimen and allowed to recover. Rats were injected with Antide or veh $6 \mathrm{~h}$ before each NORT. The six treatment groups were: blank implant+veh+veh (Blk; $n=10)$; blank implant+PCP+veh (PCP: $n=9)$; blank implant+PCP+Antide (PCP+Ant: $n=10)$; $E$ implant+PCP+veh (PCP+E: $n=10)$. As additional controls, other females were 
blank implant+veh+Antide (Ant: $n=7) ; E$ implant+veh+veh $(E: n=10)$. Females were tested twice, with 4-6d between tests. Locomotion tests occurred before and after Antide/veh administration.

\subsubsection{Expt 2. Effect of PCP, estradiol, and Antide on GAD67 expression}

Rats were treated as in Expt. 1. In place of the first NORT, rats were sacrificed for western blot procedure above. Final group numbers for dorsal hippocampal western blots were Blk n=11, PCP n=10, PCP+Ant n=7, PCP+E n=12, Ant n=7, E n=9. Final group numbers for prelimbic western blots were Blk n=9, PCP n=10,PCP+Ant n=11, $P C P+E n=11$, Ant n=8, E n=9.

\subsubsection{Expt 3. Effect of PCP, estradiol, and Antide on parvalbumin-expressing cells} Immediately after the second NORT, rats from Expt. 1 were anesthetized, perfused, and brains were analyzed using the immunohistochemistry and cell-counting protocol above. Final group numbers were Blk $n=10, P C P n=8, P C P+A n t n=10, P C P+E$ $\mathrm{n}=8$, Ant $\mathrm{n}=8, \mathrm{E} \mathrm{n}=8$.

\subsubsection{Expt 4. Effects of hippocampal infusion of GABAergic drugs on NORT}

Rats were ovariectomized, implanted with Blk or E capsules, fitted with guide cannulae, and treated with PCP or vehicle. During PCP washout, animals were habituated to the infusion procedure (see supplement). For behavioral testing, each female was infused with drug or vehicle $(0.5 \mu \mathrm{l}$ sterile saline/side) $20-25 \mathrm{~min}$ before NORT.

Expt 4A. To determine if the $\mathrm{GABA}_{\mathrm{A}}$ agonist muscimol reverses NORT deficits induced by PCP, ovx, PCP-treated females $(n=10)$ received muscimol (200ng/0.5 LL/side; Sigma Aldrich, St. Louis, MO) or vehicle prior to NORT. Animals were infused in a repeated-measures counterbalanced design with three NORT tests under both control and muscimol conditions, with 4-6d between tests. 
To assess locomotion animals received three locomotion tests: the day before the first NORT (no infusion), immediately after the second NORT (infusion of first drug), and immediately after the fifth NORT (infusion of second drug).

Expt 4B. To determine if the $\mathrm{GABA}_{A}$ antagonist bicuculline methiodide (bicuculline) blocks NORT performance in ovx females, similar to the effect of PCP, Blk animals $(n=8)$ received either bicuculline (250ng/0.5 $\mu \mathrm{l} / \mathrm{side}$; Sigma Aldrich, St. Louis, MO) or vehicle in a repeated-measures, counterbalanced design. Drug administration parameters and behavioral testing were identical to Expt. 4A.

Expt 4 C. To determine if decreasing GABA synthesis also blocks NORT performance in ovx females, Blk females $(n=6)$ received either L-allylglycine (LAG; $20 \mu \mathrm{g} / 0.5 \mu \mathrm{l} / \mathrm{side})$, or vehicle in a repeated-measures, counterbalanced design identical to Expt. 4A.

Expt 4D. To determine if the $\mathrm{GABA}_{\mathrm{A}}$ antagonist bicuculline prevents the ability of $E$ to rescue NORT performance deficits caused by PCP, PCP+E females received infusions of either bicuculline $(n=6,250 \mathrm{ng} / 0.5 \mu \mathrm{l} / \mathrm{side})$ or vehicle $(n=6)$ in an independent groups design. Females underwent 3 tests with 4-6d between tests. Locomotion tests occurred immediately after the second NORT.

After testing, animals from Expts 4A-D were anesthetized, decapitated, and cannulae placement was verified using cresyl violet staining (see supplement).

\subsection{Statistical Analysis}

Data are expressed as mean \pm SEM. NORT data, total object exploration, western blot, and PV cell counts were analyzed using one-way ANOVA. Data from each female were averaged prior to determination of group means. Locomotion tests were analyzed using two-way repeated-measures ANOVA, with treatment group and test number as the two factors. NORT data for drug-infused animals and left-right object preference were analyzed using within-subjects t-tests. Pairwise t-tests with pooled 
standard deviation were used to compare groups of pre-determined interest after ANOVA (Blk vs. each other treatment group, $P C P$ vs. $P C P+A n t$, and PCP vs. $P C P+E$ ), and the Benjamini-Hochberg false-discovery rate method was used to correct for multiple comparisons (Benjamini and Hochberg 1995). An alpha of .05 was used as the threshold for statistical significance. Data were verified to fit the assumptions of statistical tests before their use (see supplement S8-S12). All statistical tests were performed using $\mathrm{R}$. 


\section{RESULTS}

\subsection{Expt 1. Estradiol and Antide mitigate PCP-induced memory loss. Sub-} chronic PCP treatment caused loss of recognition memory (Fig 1), which was rescued by inhibition of $\mathrm{LH}$ with Antide (a $\mathrm{GnRH}$ antagonist) or treatment with estradiol. There was a significant effect of treatment on discrimination index in NORT $\left(F_{5,50}=6.54\right.$, $p=.000095$, Fig 1B). Subchronic PCP caused deficits of object recognition memory relative to Blk controls (PCP vs. Blk $\mathrm{p}=.002)$. Antide rescued recognition memory in PCP-treated animals (PCP+Ant vs. PCP $p=.0002 ; \mathrm{PCP}+$ Ant vs. Blk $p=.44)$. Estradiol replacement after ovariectomy prevented PCP-induced loss of recognition memory $(P C P+E$ vs. PCP $p=.00004 ; P C P+E$ vs. Blk p=.23). Estradiol and Antide had no significant effect on recognition memory in non-PCP-treated control animals (E vs. Blk $p=.063$; Ant vs. Blk p=.35, see supplement $\mathrm{S} 1$ for details). Consistent with this, each treatment group other than the PCP group showed strong novel object recognition, as evidenced by the significantly greater amount of time spent exploring the novel than the familiar object (Fig 1C,: PCP $p=.30$, all other groups $p<.012$ ).

Performance in NORT was not attributable to differences in exposure to objects during the exploration trial (Fig 1D). There was no significant effect of treatment on total object exploration during the exposure trial $\left(F_{5,50}=.80, p=.55\right)$. Moreover, no left-right object preferences within groups were found $(B l k p=.45, P C P p=.18, P C P+A n t p=.60$, Ant $p=.68, P C P+E p=.46, E p=.77)$.

Differences in NORT performance were not caused by differences in locomotion (Fig 1E): There was no significant main effect or interaction between group treatment or drug injection/test number on lines crossed during locomotion testing (treatment $F_{5,50}=.86$, $p=.51$; test number $F_{1,50}=0.00, p=.98$; treatment-test number $F_{5,50}=.69, p=.64$ ).

3.2. Expt 2. Effect of PCP, estradiol, and Antide on GAD67 expression. In the dorsal hippocampus, PCP decreased GAD67 expression (Fig 2A). Antide reversed this 
effect of PCP, restoring GAD67 to baseline expression, whereas estradiol failed to restore GAD67 in PCP-treated females. That is, western blots showed a significant difference between treatment groups in GAD67 expression in the dorsal hippocampus (one-way ANOVA: $F_{5,50}=3.3, p=.012$ ). Subsequent analysis indicated that subchronic PCP treatment caused a $\sim 20 \%$ reduction of GAD67 in dorsal hippocampus (PCP vs. Blk $p=.014$, see supplement S2 for details). Antide restored hippocampal GAD67 to control levels in PCP-treated animals (PCP+Ant vs. PCP $p=.0071 ; P C P+A n t$ vs. Blk $p=.44)$. PCP animals implanted with estradiol still showed a 20\% GAD67 deficit (PCP+E vs. PCP $p=.59 ; P C P+E$ vs. Blk $p=.036)$. In non-PCP-treated controls, neither Antide nor estradiol caused statistically significant differences in hippocampal GAD67 (Ant vs. Blk $p=.68, E$ vs. Blk $p=.81)$. There were no significant differences in $\beta$-actin expression across treatment groups (one-way ANOVA: $F_{5,50}=.28, p=.92 ;$ Fig $S 2 A$ ).

In the prelimbic cortex (Fig 2B) there was no clear effect of PCP, estradiol, or Antide on GAD67 expression. Western blotting revealed a significant effect of treatment on GAD67 expression in prelimbic cortex $\left(F_{5,50}=3.3, p=.012\right)$. However post-hoc tests revealed no significant differences between PCP and Blk (Blk vs. PCP p=.77, see supplement S3 for details). There were no significant differences in $\beta$-actin expression across treatment groups (one-way ANOVA: $F_{5,50}=.17, p=.97$; Fig S2B).

\subsection{Expt 3. Effect of PCP, estradiol, and Antide on the number of PV}

immunoreactive cells. These treatments did not clearly affect the number of PV expressing cells in the brain regions examined (Fig 3). No significant differences in number of PV-immunoreactive cells were found in either the prelimbic cortex (Fig 3A,

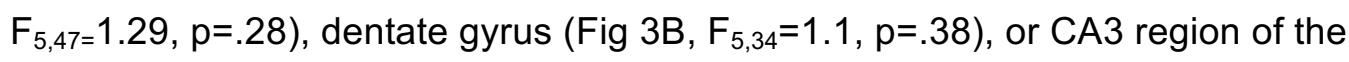
hippocampus (Fig $3 C, F_{5,35}=2.37, p=.059$ ). Although there was a significant effect of treatment on PV-expressing cell number in CA1 of the hippocampus (Fig 3D, $F_{5,35}=2.51$, 
$\mathrm{p}=.048$ ), PCP did not differ significantly from control, and post-hoc tests were unable to localize any statistically significant differences (see supplement $\$ 4$ for $p$-values).

\subsection{Expt 4. Stimulation of GABA receptors in the hippocampus reverses PCP- induced memory loss, and blocking hippocampal GABA receptors or synthesis causes memory loss.}

Infusion of the $\mathrm{GABA}_{\mathrm{A}}$ receptor agonist muscimol into the dorsal hippocampus counteracted the amnesic effects of PCP (Fig 4A-B). Consistent with Expt 1, PCPtreated animals did not show novel object recognition, as there was no clear differential exploration of the novel object $(p=.50)$. Infusion of $\mathrm{GABA}_{\mathrm{A}}$ receptor agonist muscimol into dorsal hippocampus rescued recognition memory in PCP-treated ovx females, as evidenced by both the discrimination index $(p=.010)$ and difference in exploration times of the known and novel objects $(p=.0044)$. Differences in NORT performance were not due to differences in object exploration during exposure trial (t-test $p=.53$ ), and no leftright object preferences were found $(P C P+$ muscimol $p=.49, P C P+v e h p=.61$, Fig S3A). Moreover, there was no significant main effect or interaction of treatment or test number on lines crossed in locomotion tests (Fig S4A, and see supplement S5).

Blocking $\mathrm{GABA}_{\mathrm{A}}$ receptors in the dorsal hippocampus caused memory loss that was comparable to that observed following PCP administration (Fig 4C-D). Infusion of $\mathrm{GABA}_{\mathrm{A}}$ receptor antagonist bicuculline into the dorsal hippocampus of control (non-PCP treated) females caused loss of recognition memory (discrimination index $p=.0011$; known vs. novel: Blk+veh $p=.00016$, Blk+bicuculline $p=.72$ ). Differences in NORT performance were not due to differences in exploration during the exposure trial $(p=.36$, Fig S3B), left-right preferences (Blk+bicuculline $p=.55$, Blk+veh $p=.65$ ), or locomotion differences (Fig S4B, see supplement S6).

Consistent with the effect of $\mathrm{GABA}_{\mathrm{A}}$ receptor antagonism, blocking GABA synthesis in the dorsal hippocampus also caused memory loss. Infusion of the GAD inhibitor LAG 
into the dorsal hippocampus of control (non-PCP treated) females caused loss of recognition memory (discrimination index $p=.022$; known vs novel: veh $p=.0027$, LAG $p=.36)$. There were no significant differences in exploration during the exposure trial $(p=.12$, Fig S3C) or left-right preference $($ LAG $p=.95$, veh $p=.40)$. Although there was a significant effect of treatment on locomotion, post hoc analysis found no differences in locomotion following administration of LAG vs. vehicle ( $p=.41$, Fig S4C). The only significant difference found was between testing before treatment and testing after administration of vehicle $(p=.018)$.

Blocking $\mathrm{GABA}_{\mathrm{A}}$ receptors in dorsal hippocampus also eliminated estradiol's rescue of memory in PCP-treated females (Fig 4E-F). Dorsal hippocampal infusion of bicuculline impaired novel object discrimination in PCP-treated animals that were implanted with estradiol (discrimination index $p=.016$; known vs. novel: $E+P C P+v e h$ $p=.009, E+P C P+$ bicuculline $p=.90)$. There were no differences in object exploration during the exposure trial (t-test $p=.11$, Fig S3D), left-right preferences within groups $(E+P C P+$ bicuculline $p=.76, E+P C P+$ veh $p=.18)$, or locomotion differences $(p=.46$, Fig S4D).

Cresyl violet histology verified that infusion cannulae were appropriately placed in dorsal hippocampus (Fig 5). 
Riordan 16

\section{DISCUSSION}

Here we demonstrate that modulation of $\mathrm{LH}$ and estradiol can rescue recognition memory in an NMDAR antagonist model of schizophrenia. We found that PCP decreased expression of hippocampal GAD67, an effect that was reversed by inhibition of $\mathrm{LH}$, but not administration of E. Localized hippocampal infusion of the GABA agonist muscimol reversed NORT deficits induced by PCP. Consistent with this, the GABA antagonist bicuculine or GAD-inhibitor LAG decreased NORT in ovx females and blocked enhancement of NORT exerted by E in PCP-treated females. This suggests that GABAergic changes may contribute both to PCP's disruption of recognition memory and the hormones' ability to counteract this effect. Importantly, the observed effects are not due to changes in locomotion or object exploration during the exposure trial.

These findings are consistent with the idea that PCP-induced amnesia is mediated by GABAergic disruptions specific to dorsal hippocampus. PCP reduced expression of hippocampal GAD67, which presumably decreases the amount of GABA available for release when inhibitory neurons fire (Lewis et al. 2012). Previous studies suggest that a reduction of GAD67 can upset the excitatory-inhibitory balance in dorsal hippocampus, which is thought to be an important component of short-term memory (Lewis et al. 2012; Lisman 2010; Sigurdsson et al. 2010). Our data then suggest a causal link between this localized GABAergic deficit and PCP-induced loss of recognition memory. Because dorsal hippocampal infusion of a $G_{A B A}$ agonist rescued recognition memory in $\mathrm{PCP}$-treated females and infusion of a $\mathrm{GABA}_{\mathrm{A}}$ antagonist and GABA synthesis blocker produced memory loss similar to that of PCP, our data are consistent with the notion that disrupted GABA transmission in the hippocampus is both necessary and sufficient for PCP's amnesic effects in this animal model. These findings complement previous work showing that complete lesions of dorsal hippocampus cause loss of object recognition memory in rodents, and support the idea that aberrant signals 
from the hippocampus may be capable of disrupting forms of object recognition typically thought to reside in regions such as perirhinal cortex (Broadbent et al. 2004; Cohen et al. 2013; Oliveira et al. 2010). Caution with the interpretation that a reduction in GAD67 underlies the memory deficit is warranted, however, as we did not directly rescue hippocampal GAD67 in PCP-treated animals. It is possible that our muscimol infusions stimulated $\mathrm{GABA}_{\mathrm{A}}$ receptors to a greater extent than rescuing GAD67 would have (Hafting et al. 2008). As such the present results imply localization of PCP's effects to dorsal hippocampus but do not provide direct evidence that decreased GAD67 causes the memory loss (Hafting et al. 2008).

These data suggest that the prefrontal cortex does not play a role in the effects of PCP on object recognition memory. This notion is supported by studies showing that lesioning prefrontal cortex does not affect performance in NORT and related tasks (Barker and Warburton 2011). Although other investigations have found that NMDAR antagonists cause loss of GAD67 specific to PV neurons in prelimbic cortex, these studies did not measure overall regional expression of GAD67 (Amitai et al. 2012; Behrens et al. 2007; Kinney et al. 2006). Because PV-expressing neurons are estimated to make up only $30-40 \%$ of the inhibitory neurons in rat frontal cortex, it is possible that PV-neuron-specific deficits of GAD67 were masked in our study by unaffected GAD67 within other GABAergic neuronal subtypes (Xu et al. 2010).

We did not observe a change in the expression of PV, a result that is inconsistent with some and consistent with other previous research. There is a current conflict as to whether NMDAR antagonists cause a long-term reduction of PV-expressing cells in cortex and hippocampus (Abdul-Monim et al. 2007; Behrens et al. 2007; Benneyworth et al. 2011; Rujescu et al. 2006; Turner et al. 2010; Wang et al. 2008). Such inconsistencies suggest that PCP's effect on PV expression may be variable across different rat strains, sexes, or PCP doses. Overall, this lack of observed differences in 
PV cell counts suggests that PCP does not disrupt recognition memory by eliminating PV-expressing cells.

The present results suggest that either increasing $\mathrm{E}$ or decreasing LH may counteract loss of recognition memory in schizophrenia, supporting the idea that E's therapeutic mechanisms include suppression of LH. PCP-induced memory loss occurred only in animals with high LH (i.e., Blk group), and inhibiting LH reversed this amnesic effect. As in previous studies, estradiol-treated animals, that also exhibit low LH, were invulnerable to PCP's effects in the present paradigm (Roseman et al. 2012; Sutcliffe et al. 2008). As LH and its analogues are capable of disrupting memory on their own (Burnham et al. 2016; Burnham and Thornton 2015; Ziegler and Thornton 2010), our data indicate that both LH and PCP can impair memory. The marked increase in incidence of schizophrenia at menopause (McGregor et al. 2017) may be explained by such a combined mechanism, whereby high levels of LH interact with genetic or environmental factors in vulnerable individuals, leading to an increased probability in the onset of schizophrenia. Given that Antide was able to rescue recognition memory long after PCP washout, our data suggest that inhibiting LH might be able to restore some forms of memory in such affected individuals.

These data indicate that LH may affect hippocampal GABA neurotransmission, a relationship that has not been previously characterized. Inhibition of $\mathrm{LH}$ with Antide restored hippocampal GAD67 in PCP-treated animals to baseline control levels. LH has been found in the cytoplasm of hippocampal neurons in both rats and humans, and receptors for $\mathrm{LH}$ are found on neurons in the same region (Burnham and Thornton 2015). Currently, the mechanism through which LH affects GABA is unknown. One speculative possibility is that binding of $\mathrm{LH}$ to hippocampal $\mathrm{LH}$ receptors causes second messenger cascades that downregulate production of GAD67. This anti-GABAergic action could be responsible, at least in part, for the $\mathrm{LH}$-induced cognitive impairment 
observed in this and other contexts (Burnham et al. 2016; Burnham and Thornton 2015; Casadesus et al. 2007; Ziegler and Thornton 2010).

Interestingly, estradiol reversed PCP's amnesic effects but did not restore GAD67 expression in the hippocampus, leaving its mechanisms of memory rescue unknown. This is surprising, because estradiol inhibits release of $\mathrm{LH}$ and should have similar effects as Antide (Charlton 2008; Wise and Ratner 1980). However it is known that under constant E, animals still exhibit daily LH surges (Legan et al. 1975), indicating that $\mathrm{E}$ may be less effective than Antide at consistently suppressing $\mathrm{LH}$ (Ziegler and Thornton 2010). Still, $\mathrm{GABA}_{\mathrm{A}}$ receptor inhibition blocked estradiol's rescue of memory, supporting the notion that at least some of estradiol's effects are dependent on the hippocampal GABA system. Estradiol has been shown to enhance $\mathrm{GABA}_{\mathrm{A}}$ receptor binding in a number of brain regions, including the hippocampus, and hence may be reversing PCP's effects by upregulating GABA receptors (Schumacher et al. 1989). Additionally, estradiol's effects on hippocampal spine density or brain-derived neurotrophic factor could account for its ability to rescue memory, either through enhancement of GABA signaling (Ohba et al. 2005) or other mechanisms (Li et al. 2004; Wu et al. 2013).

These results may have clinical implications. Namely, our data provide conceptual support for models in which declarative memory loss in schizophrenia is caused by disrupted hippocampal inhibitory function (Lewis et al. 2012; Nakazawa et al. 2012). Hippocampal GABA abnormalities are reliably found in schizophrenia and other conditions such as bipolar disorder, and it is possible that selective GABAergic modulation could mitigate memory loss in such disorders (Benes et al. 2007; Curley et al. 2011; Lewis et al. 2012). These data also indicate that the hypothalamic-pituitarygonadal axis may be an unexploited tool to aid in understanding mechanisms of cognitive loss in schizophrenia. 
bioRxiv preprint doi: https://doi.org/10.1101/207159; this version posted October 21, 2017. The copyright holder for this preprint (which was not certified by peer review) is the author/funder. All rights reserved. No reuse allowed without permission.

Riordan 20

In conclusion, we demonstrate that inhibiting luteinizing hormone can rescue memory in an NMDAR-antagonist model of schizophrenia. Our data suggest that GABAergic loss specific to the dorsal hippocampus contributes to PCP- and LH-induced disruption of recognition memory. 
Riordan 21

\section{FUNDING AND DISCOLOSURES}

Work was funded by Oberlin Grant-in-Aid and a Robert Rich Grant, from Oberlin

College. The authors declare no conflicts of interest.

\section{ACKNOWLEDGEMENTS}

We would like to thank Carey Lyons, Alexander Goldberg, Molly Martorella, and Hannah Rodgers for technical assistance. 


\section{REFERENCES}

Abdul-Monim Z, Neill JC, Reynolds GP. 2007. Sub-chronic psychotomimetic phencyclidine induces deficits in reversal learning and alterations in parvalbuminimmunoreactive expression in the rat. J Psychopharmacol 21(2):198-205.

Amitai N, Kuczenski R, Behrens MM, Markou A. 2012. Repeated phencyclidine administration alters glutamate release and decreases GABA markers in the prefrontal cortex of rats. Neuropharmacology 62(3):1422-31.

Barker GR and Warburton EC. 2011. When is the hippocampus involved in recognition memory? J Neurosci 31(29):10721-31.

Beasley CL and Reynolds GP. 1997. Parvalbumin-immunoreactive neurons are reduced in the prefrontal cortex of schizophrenics. Schizophr Res 24(3):349-55.

Behrens MM, Ali SS, Dao DN, Lucero J, Shekhtman G, Quick KL, Dugan LL. 2007. Ketamine-induced loss of phenotype of fast-spiking interneurons is mediated by NADPH-oxidase. Science 318(5856):1645-7.

Benes FM, Lim B, Matzilevich D, Walsh JP, Subburaju S, Minns M. 2007. Regulation of the GABA cell phenotype in hippocampus of schizophrenics and bipolars. Proc Natl Acad Sci U S A 104(24):10164-9.

Benjamini $Y$ and Hochberg Y. 1995. Controlling the false discovery rate: A practical and powerful approach to multiple testing. Journal of the Royal Statistical Society.Series B (Methodological) :289-300.

Benneyworth MA, Roseman AS, Basu AC, Coyle JT. 2011. Failure of NMDA receptor hypofunction to induce a pathological reduction in PV-positive GABAergic cell markers. Neurosci Lett 488(3):267-71.

Broadbent NJ, Squire LR, Clark RE. 2004. Spatial memory, recognition memory, and the hippocampus. Proc Natl Acad Sci U S A 101(40):14515-20.

Burnham V, Sundby C, Laman-Maharg A, Thornton J. 2016. Luteinizing hormone acts at the hippocampus to dampen spatial memory. Horm Behav 89:55-63.

Burnham VL and Thornton JE. 2015. Luteinizing hormone as a key player in the cognitive decline of alzheimer's disease. Horm Behav 76:48-56.

Casadesus G, Milliken EL, Webber KM, Bowen RL, Lei Z, Rao CV, Perry G, Keri RA, Smith MA. 2007. Increases in luteinizing hormone are associated with declines in cognitive performance. Mol Cell Endocrinol 269(1-2):107-11.

Charlton H. 2008. Hypothalamic control of anterior pituitary function: A history. J Neuroendocrinol 20(6):641-6. 
Riordan 23

Cohen SJ, Munchow AH, Rios LM, Zhang G, Ásgeirsdóttir HN, Stackman RW. 2013. The rodent hippocampus is essential for nonspatial object memory. Current Biology 23(17):1685-90.

Curley AA, Arion D, Volk DW, Asafu-Adjei JK, Sampson AR, Fish KN, Lewis DA. 2011. Cortical deficits of glutamic acid decarboxylase 67 expression in schizophrenia: Clinical, protein, and cell type-specific features. Am J Psychiatry 168(9):921-9.

Green MF, Kern RS, Heaton RK. 2004. Longitudinal studies of cognition and functional outcome in schizophrenia: Implications for MATRICS. Schizophr Res 72(1):41-51.

Hafting T, Fyhn M, Bonnevie T, Moser MB, Moser El. 2008. Hippocampus-independent phase precession in entorhinal grid cells. Nature 453(7199):1248-52.

Janhunen SK, Svard H, Talpos J, Kumar G, Steckler T, Plath N, Lerdrup L, Ruby T, Haman M, Wyler R, et al. 2015. The subchronic phencyclidine rat model: Relevance for the assessment of novel therapeutics for cognitive impairment associated with schizophrenia. Psychopharmacology (Berl) 232(21-22):4059-83.

Jones C, Watson D, Fone K. 2011. Animal models of schizophrenia. Br J Pharmacol 164(4):1162-94.

Kaalund SS, Riise J, Broberg BV, Fabricius K, Karlsen AS, Secher T, Plath N, Pakkenberg B. 2013. Differential expression of parvalbumin in neonatal phencyclidine-treated rats and socially isolated rats. J Neurochem 124(4):548-57.

Kinney JW, Davis CN, Tabarean I, Conti B, Bartfai T, Behrens MM. 2006. A specific role for NR2A-containing NMDA receptors in the maintenance of parvalbumin and GAD67 immunoreactivity in cultured interneurons. J Neurosci 26(5):1604-15.

Legan SJ, Allyn Coon G, Karsch FJ. 1975. Role of estrogen as initiator of daily LH surges in the ovariectomized rat 12 . Endocrinology 96(1):50-6.

Lewis DA, Curley AA, Glausier JR, Volk DW. 2012. Cortical parvalbumin interneurons and cognitive dysfunction in schizophrenia. Trends Neurosci 35(1):57-67.

Leys C, Ley C, Klein O, Bernard P, Licata L. 2013. Detecting outliers: Do not use standard deviation around the mean, use absolute deviation around the median. $\mathrm{J}$ Exp Soc Psychol 49(4):764-6.

Li C, Brake WG, Romeo RD, Dunlop JC, Gordon M, Buzescu R, Magarinos AM, Allen PB, Greengard P, Luine V, et al. 2004. Estrogen alters hippocampal dendritic spine shape and enhances synaptic protein immunoreactivity and spatial memory in female mice. Proc Natl Acad Sci U S A 101(7):2185-90.

Lisman J. 2010. Working memory: The importance of theta and gamma oscillations. Current Biology 20(11):R490-2. 
McGrath J, Saha S, Chant D, Welham J. 2008. Schizophrenia: A concise overview of incidence, prevalence, and mortality. Epidemiologic Reviews 30(1):67-76.

McGregor C, Riordan A, Thornton J. 2017. Estrogens and the cognitive symptoms of schizophrenia: Possible neuroprotective mechanisms. Front Neuroendocrinol .

Moghaddam B and Javitt D. 2012. From revolution to evolution: The glutamate hypothesis of schizophrenia and its implication for treatment. Neuropsychopharmacology 37(1):4-15.

Nakazawa K, Zsiros V, Jiang Z, Nakao K, Kolata S, Zhang S, Belforte JE. 2012. GABAergic interneuron origin of schizophrenia pathophysiology. Neuropharmacology 62(3):1574-83.

National Research Council of the National Academies, Editor. 2011. Guide for the care and use of laboratory animals. 8th Ed ed. Washington DC: National Academy Press.

Ohba S, Ikeda T, Ikegaya Y, Nishiyama N, Matsuki N, Yamada MK. 2005. BDNF locally potentiates GABAergic presynaptic machineries: Target-selective circuit inhibition. Cereb Cortex 15(3):291-8.

Oliveira AM, Hawk JD, Abel T, Havekes R. 2010. Post-training reversible inactivation of the hippocampus enhances novel object recognition memory. Learn Mem 17(3):155-60.

Paxinos $G$ and Watson C. 2007. The rat brain in stereotaxic coordinates. Elsevier.

Rajagopal L, Massey BW, Huang M, Oyamada Y, Meltzer HY. 2014. The novel object recognition test in rodents in relation to cognitive impairment in schizophrenia. Curr Pharm Des 20(31):5104-14.

Roseman AS, McGregor C, Thornton JE. 2012. Estradiol attenuates the cognitive deficits in the novel object recognition task induced by sub-chronic phencyclidine in ovariectomized rats. Behav Brain Res 233(1):105-12.

Rujescu D, Bender A, Keck M, Hartmann AM, Ohl F, Raeder H, Giegling I, Genius J, McCarley RW, Möller H. 2006. A pharmacological model for psychosis based on $\mathrm{N}$ methyl-D-aspartate receptor hypofunction: Molecular, cellular, functional and behavioral abnormalities. Biol Psychiatry 59(8):721-9.

Schumacher M, Coirini H, McEwen B. 1989. Regulation of high-affinity GABA A receptors in the dorsal hippocampus by estradiol and progesterone. Brain Res 487(1):178-83.

Sigurdsson T, Stark KL, Karayiorgou M, Gogos JA, Gordon JA. 2010. Impaired hippocampal-prefrontal synchrony in a genetic mouse model of schizophrenia. Nature 464(7289):763-7. 
Riordan 25

Sutcliffe JS, Rhaman F, Marshall KM, Neill JC. 2008. Oestradiol attenuates the cognitive deficit induced by acute phencyclidine treatment in mature female hooded-lister rats. J Psychopharmacol 22(8):918-22.

Turner CP, DeBenedetto D, Ware E, Stowe R, Lee A, Swanson J, Walburg C, Lambert A, Lyle M, Desai P. 2010. Postnatal exposure to MK801 induces selective changes in GAD67 or parvalbumin. Experimental Brain Research 201(3):479-88.

Wang CZ, Yang SF, Xia Y, Johnson KM. 2008. Postnatal phencyclidine administration selectively reduces adult cortical parvalbumin-containing interneurons. Neuropsychopharmacology 33(10):2442-55.

Wise PM and Ratner A. 1980. Effect of ovariectomy on plasma LH, FSH, estradiol, and progesterone and medial basal hypothalamic LHRH concentrations old and young rats. Neuroendocrinology 30(1):15-9.

Wu Y, Hill R, Gogos A, Van Den Buuse M. 2013. Sex differences and the role of estrogen in animal models of schizophrenia: Interaction with BDNF. Neuroscience 239:67-83.

Xu X, Roby KD, Callaway EM. 2010. Immunochemical characterization of inhibitory mouse cortical neurons: Three chemically distinct classes of inhibitory cells. J Comp Neurol 518(3):389-404.

Zhang ZJ and Reynolds GP. 2002. A selective decrease in the relative density of parvalbumin-immunoreactive neurons in the hippocampus in schizophrenia. Schizophr Res 55(1-2):1-10.

Ziegler SG and Thornton JE. 2010. Low luteinizing hormone enhances spatial memory and has protective effects on memory loss in rats. Horm Behav 58(5):705-13. 


\section{Riordan 26}

A

\begin{tabular}{|c|c|c|c|c|c|c|}
\hline $1 d$ & & & & Expt.1,3 & Expt.2 & Expt.4 \\
\hline $\begin{array}{l}\text { Ovariectomy to eliminate } \\
\text { hormone fluctuations }+ \\
\text { Blk or E capsule implant }\end{array}$ & recovery & $\begin{array}{l}\text { Bidaily PCP or } \\
\text { veh injections }\end{array}$ & washout & $\begin{array}{l}\text { Ant or veh injections. } 2 x \text { NORT, } \\
\text { 4-6 days apart. Locomotion tests } \\
\text { (Fig 1). Perfuse for IHC (Fig 3). }\end{array}$ & $\begin{array}{l}\text { Ant or veh injections. } \\
\text { Sacrifice for western blot } \\
\text { (Fig 2). }\end{array}$ & $\begin{array}{l}\text { 3-6x NORT with muscimol, LAG, or } \\
\text { bicuculline infusions, 4-6 days apart. } \\
\text { Locomotion tests (Figs 4-5). }\end{array}$ \\
\hline
\end{tabular}

B

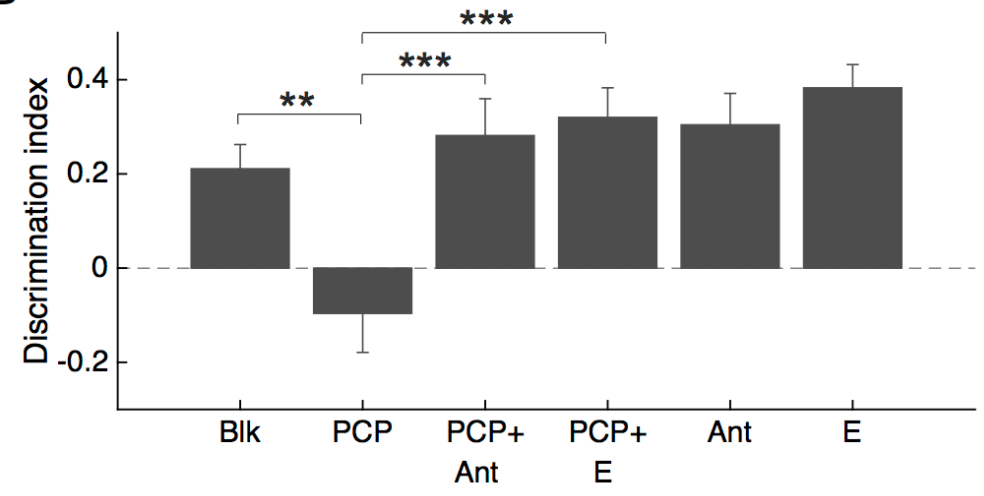

D

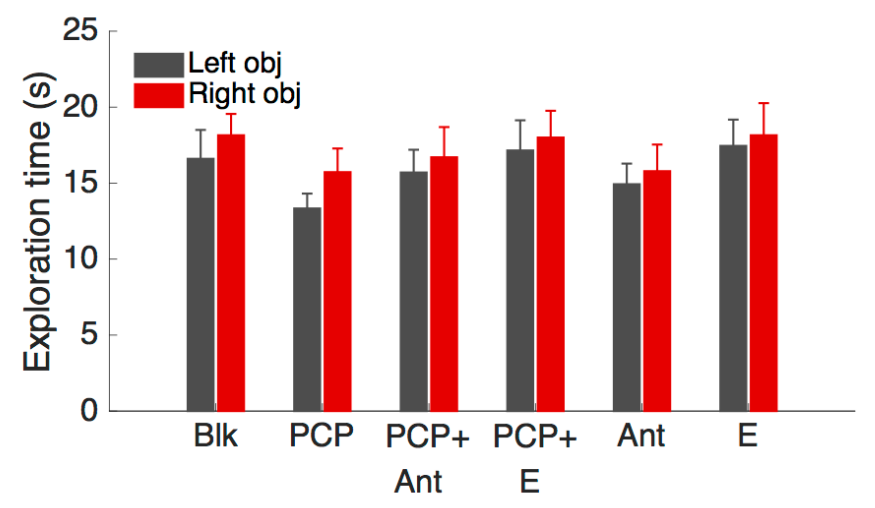

C

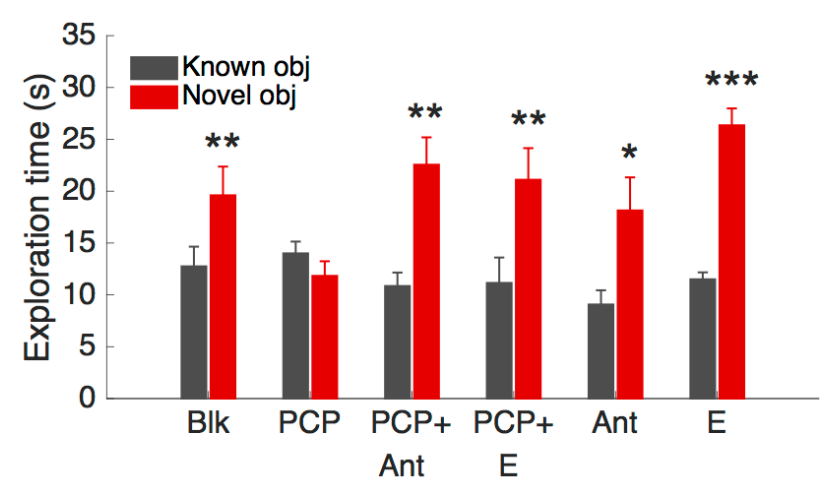

E

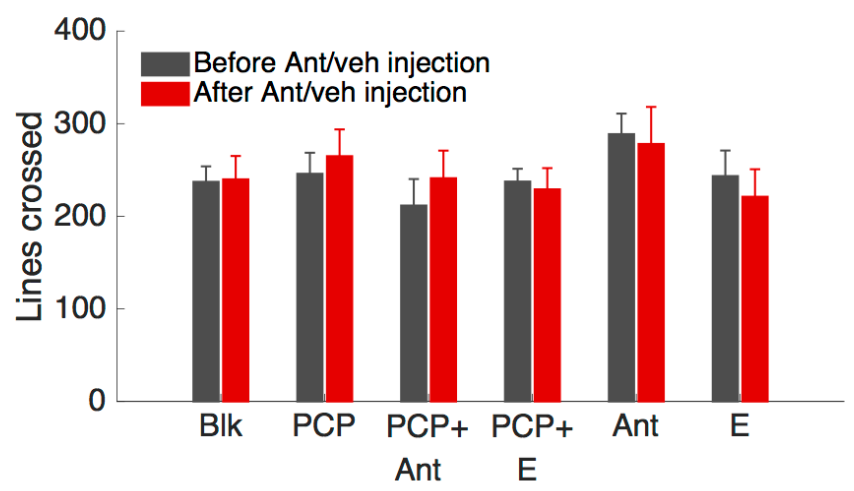

Fig 1. Suppression of LH with Antide or estradiol rescued recognition memory in ovx PCP-treated females. A. Experimental schedule B. Performance in novel object recognition task (NORT). Sub-chronic PCP disrupted object discrimination compared to vehicle (PCP vs Blk). Blocking LH with Antide reversed PCP's effects (PCP+Ant vs PCP), as did estradiol (PCP+ E). Neither Ant nor E significantly affected object discrimination relative to Blk controls. Zero represents chance performance. C. 
Exploration time for novel vs. known objects during test trial. Consistent with discrimination index analysis, each group showed preference for the novel object, with the exception of the PCP group. D. There were no significant differences in total object exploration or left-right object preference amongst any of the groups during NORT exposure trial. E. There were no significant differences in number of lines crossed during locomotion tests, either across groups or before and after drug treatments. $n=7-10$ rats/group. 2 tests/rat. Asterisks indicate statistically significant differences $\left(^{*}=p<.05\right.$, $\left.{ }^{* *}=p<.01,{ }^{* * *}=p<.001\right)$. 
Riordan 28

A

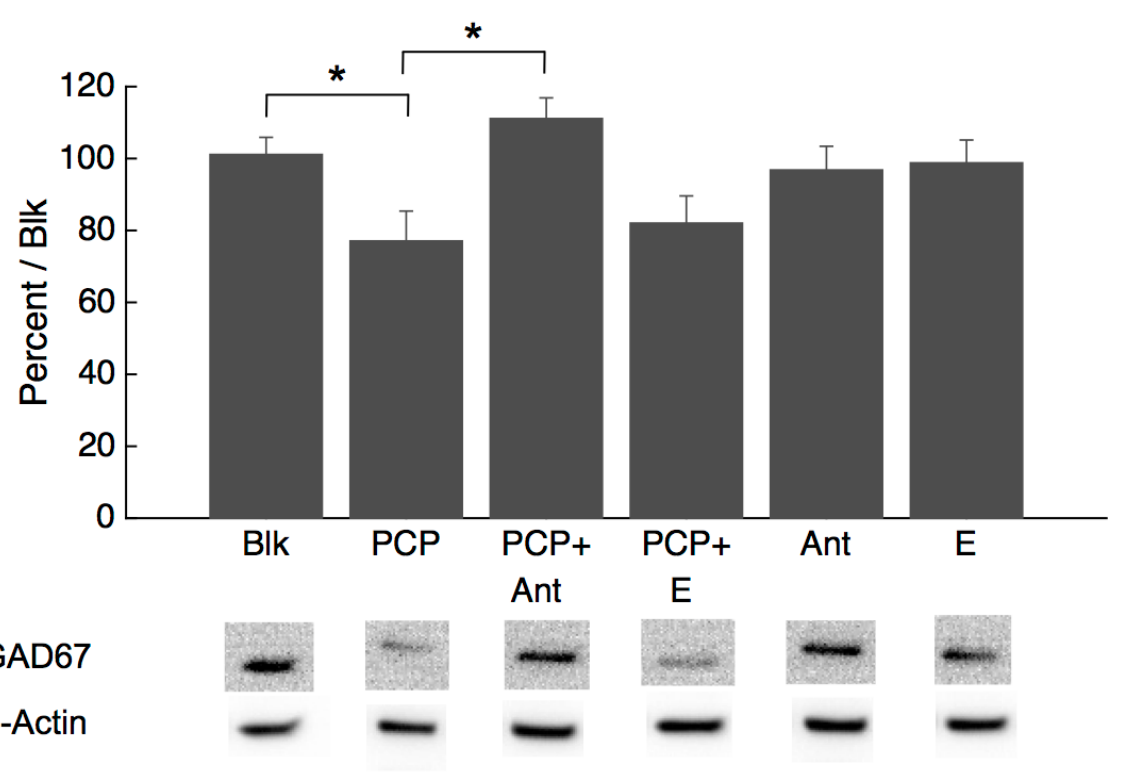

B

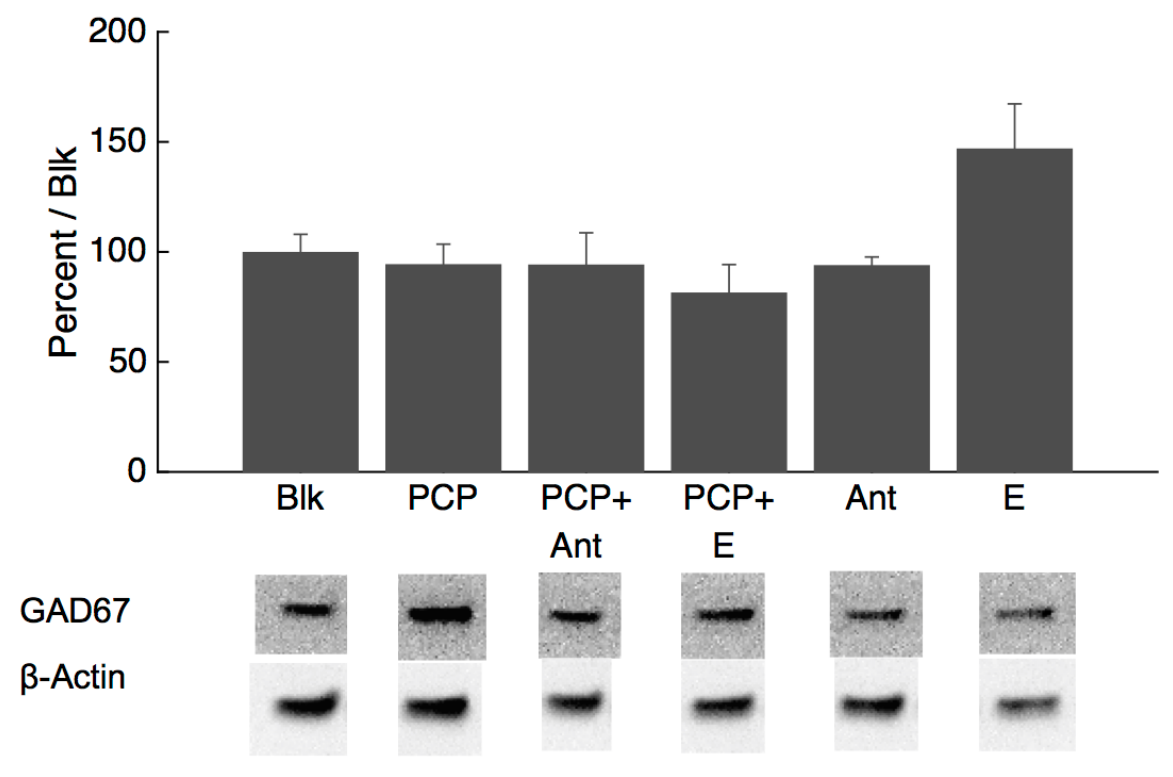

Fig 2. PCP decreased GAD67 expression in dorsal hippocampus and inhibition of $L H$ restored it. A. GAD67 expression in dorsal hippocampus, measured by western blot. 
Riordan 29

Hippocampal GAD67 was significantly decreased in PCP-treated rats relative to controls (PCP vs Blk). Inhibition of LH (PCP+ Ant) significantly increased hippocampal GAD67 (PCP+Ant vs PCP). B. GAD67 expression in prelimbic cortex. ANOVA revealed a significant difference in GAD67 expression, however post hoc tests indicated no effect of PCP (PCP vs Blk) or any other treatment. All GAD67 data were normalized over $\beta$-Actin and intra-gel blank controls. Representative blots are shown below. Original images for representative blots are shown in supplementary Fig S1. $\beta$-actin expression, shown in Fig S2, did not differ across treatment groups. $n=7-12$ rats/group. Three technical replicates were performed for hippocampal data. Asterisks indicate statistically significant differences $\left({ }^{*}=p<.05\right)$. 
bioRxiv preprint doi: https://doi.org/10.1101/207159; this version posted October 21, 2017. The copyright holder for this preprint (which was not certified by peer review) is the author/funder. All rights reserved. No reuse allowed without permission.

Riordan 30

A

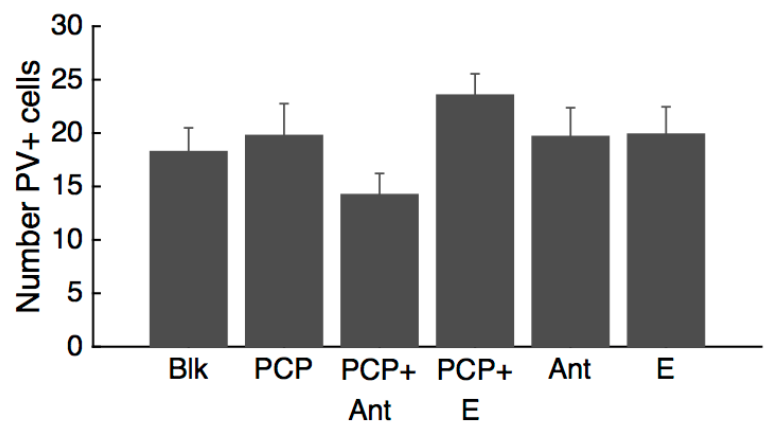

C

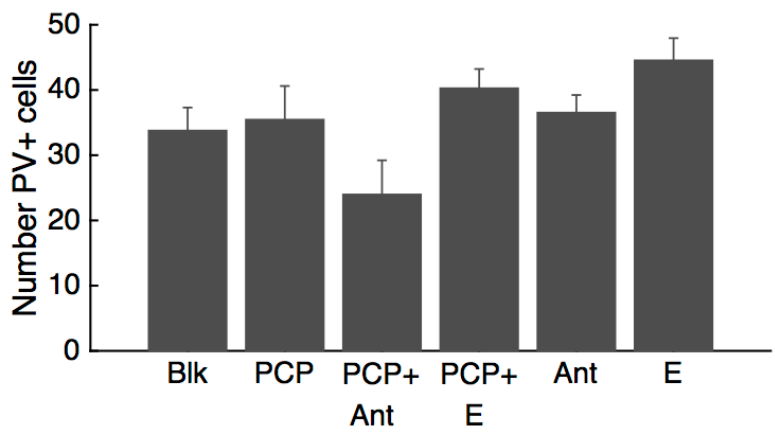

B

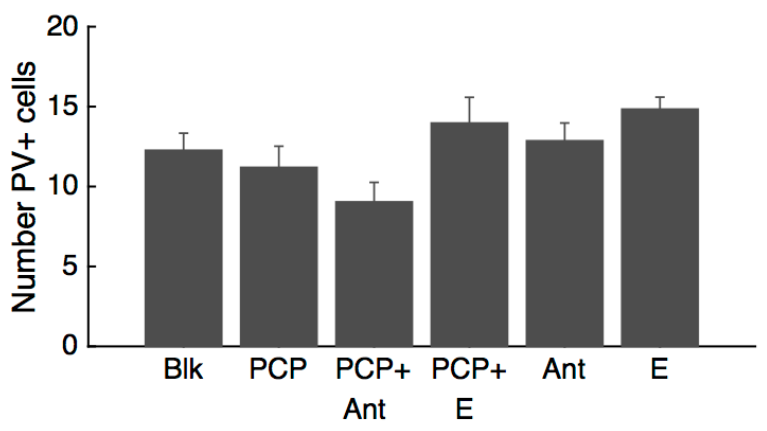

D

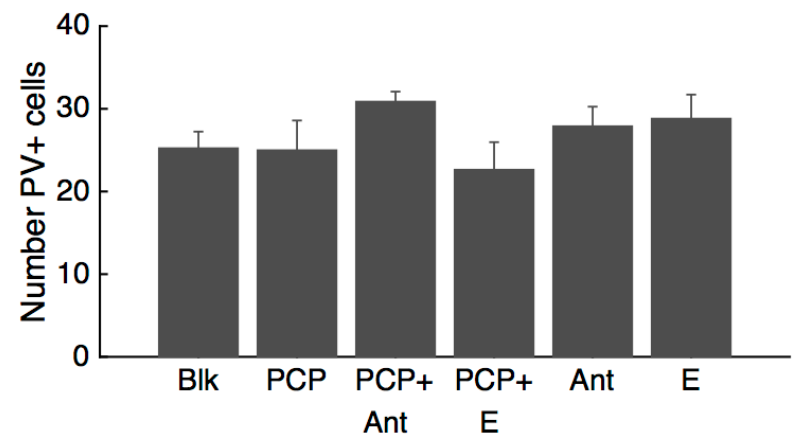

E

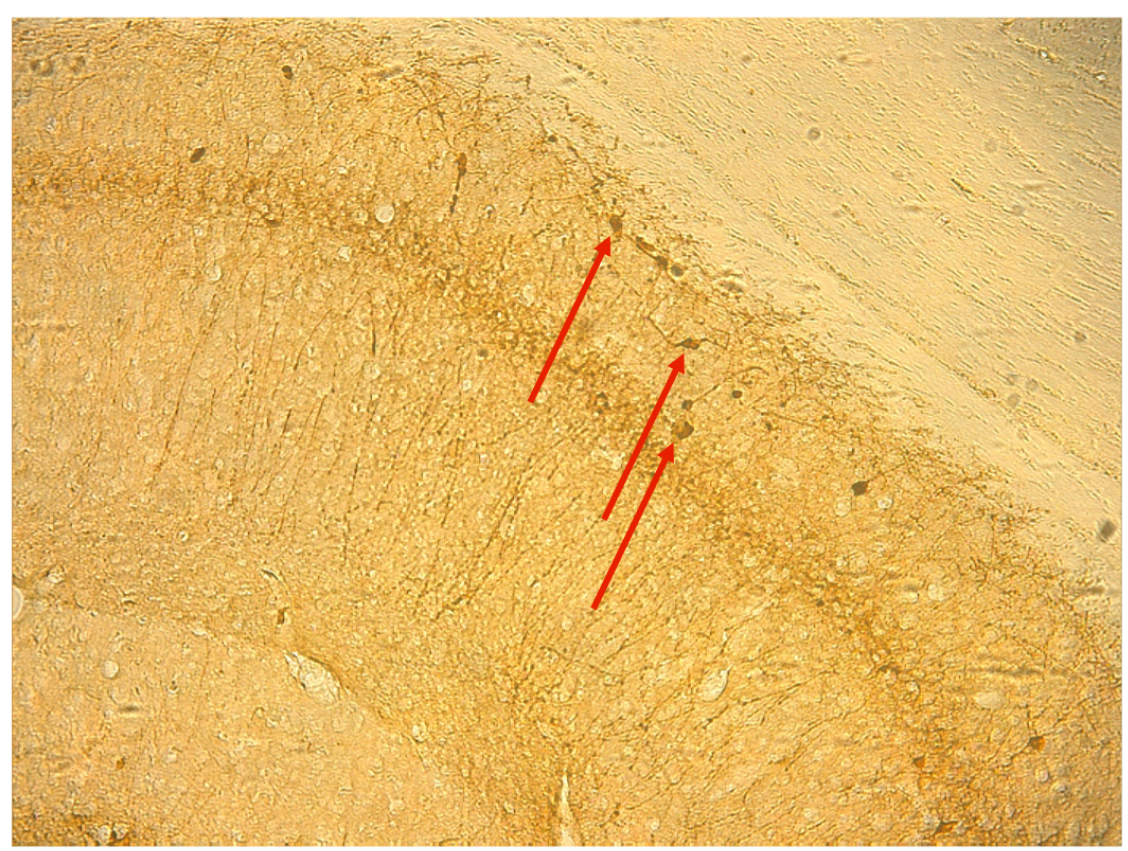


Fig 3. Number of immunoreactive parvalbumin-expressing (PV+) cells was unaffected by PCP and hormonal treatments $(n=8-10)$. ANOVA revealed no significant differences in PV cell number in the prelimbic cortex (panel A), dentate gyrus (panel B), or CA3 region of the hippocampus (panel C). ANOVA revealed a significant difference in cell counts in the CA1 region of the hippocampus $(p=.048)$, however this effect was not localizable with post hoc tests (D) and PCP did not differ significantly from control PCP vs Blk. E. Representative immunohistochemical staining against PV. Arrows point to several example cells. 
A

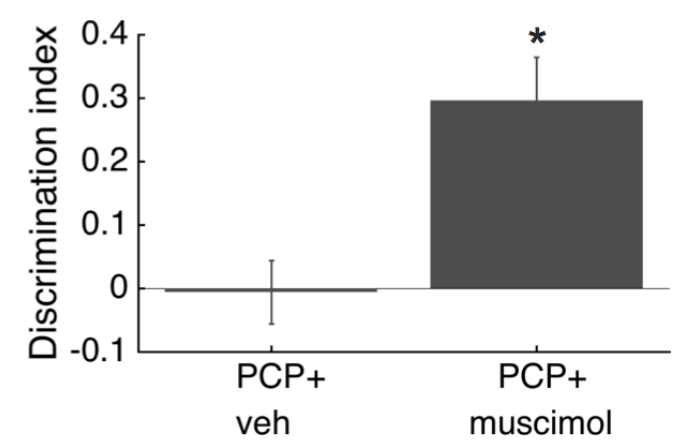

C

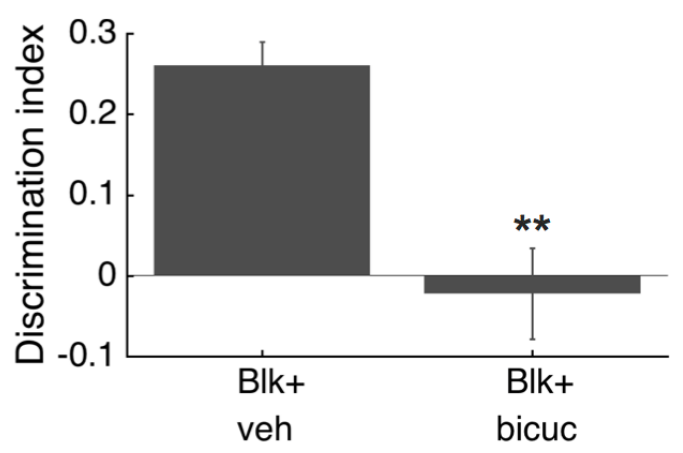

$\mathrm{E}$

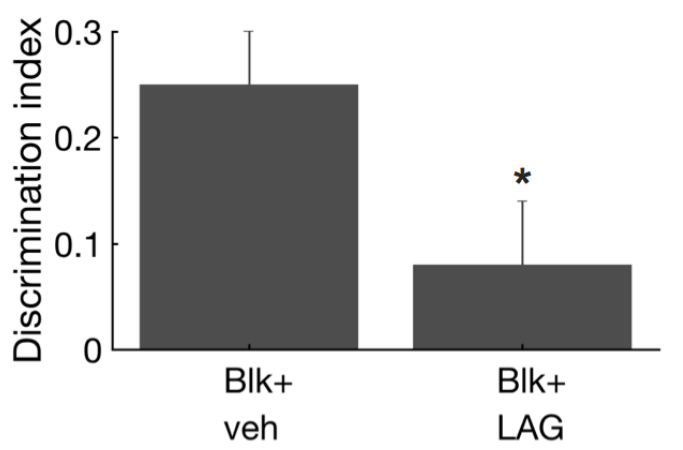

G

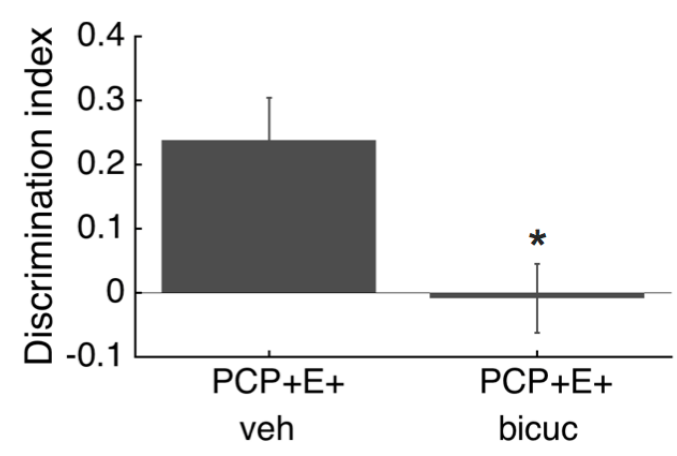

B
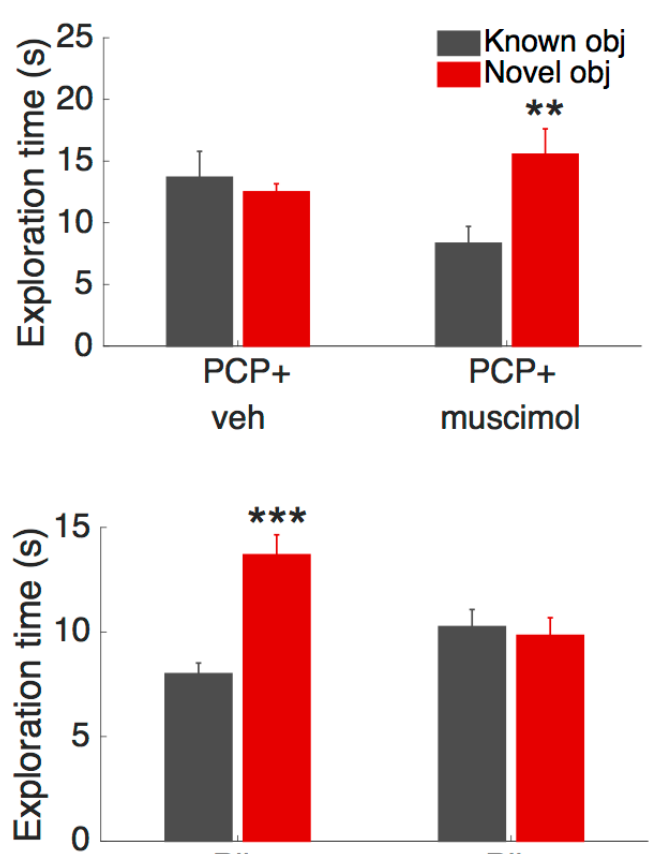

Blk+

veh bicuc

$\mathrm{F}$

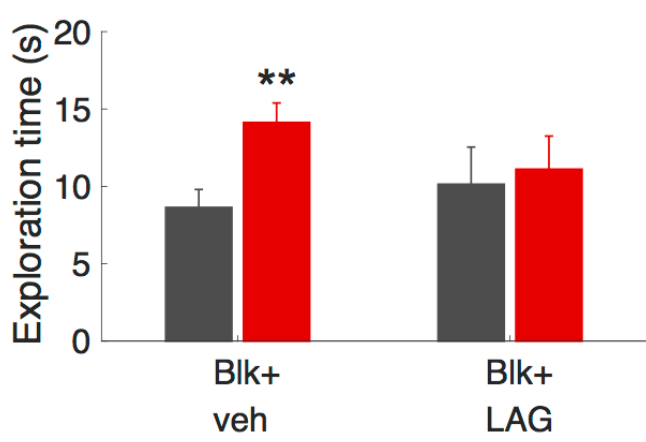

$\mathrm{H}$

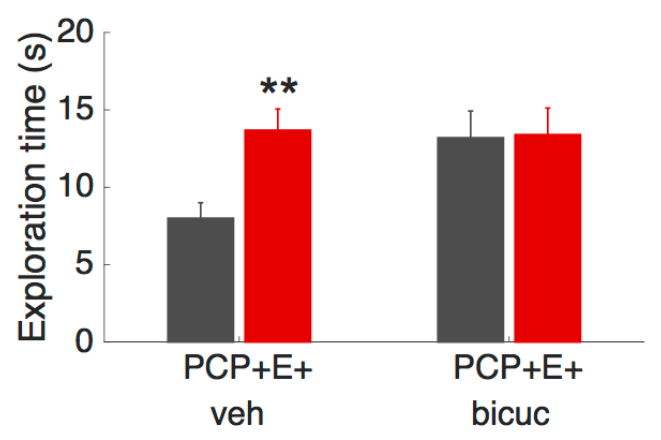

Fig 4. Stimulating hippocampal $G A B A_{A}$ receptors rescued recognition memory in PCPtreated rats. Blocking hippocampal $\mathrm{GABA}_{\mathrm{A}}$ receptors or $\mathrm{GABA}$ synthesis impaired 
recognition memory in Blk and estrogen-PCP-treated animals. A. Infusions of the $\mathrm{GABA}_{A}$ agonist muscimol into dorsal hippocampus significantly raised novel object discrimination in PCP-treated rats relative to vehicle infusion controls $(n=10,3$ tests/drug condition). B. Consistent with discrimination index, PCP animals showed chance-level exploration of novel vs. known objects after vehicle infusion and significantly greater exploration of novel objects after muscimol infusion. C. Infusions of the $\mathrm{GABA}_{\mathrm{A}}$ antagonist bicuculline into dorsal hippocampus impaired NORT performance in nonPCP-treated Blk rats ( $n=8,3$ tests/drug condition). D. Data from C expressed as exploration time (Blk+veh, Blk+bicuc). E. Similarly, infusions of the GAD inhibitor LAG into dorsal hippocampus impaired NORT performance in non-PCP-treated Blk rats $(n=8$, 3 tests/drug condition). F. Data from E expressed as exploration time (Blk+veh, Blk+bicuc). G. Infusions of $\mathrm{GABA}_{A}$ antagonist bicuculline into dorsal hippocampus disrupted NORT performance in rats treated with both PCP and estradiol $(n=6,3$ tests/animal). H. Data from $G$ expressed as exploration time. Asterisks indicate statistically significant differences compared to veh $(A, C, E)$ or to known object in same treatment group $(B, D, F) .\left({ }^{*}=p<.05,{ }^{* *}=p<.01,{ }^{* * *}=p<.001\right)$. 
bioRxiv preprint doi: https://doi.org/10.1101/207159; this version posted October 21, 2017. The copyright holder for this preprint (which was not certified by peer review) is the author/funder. All rights reserved. No reuse allowed without permission.

\section{Riordan 34}

A
- $\mathrm{PCP}+$ musc
$\Delta$ Blk + bicuc
o $E+$ veh
- $E+$ bicuc
- Blk + LAG

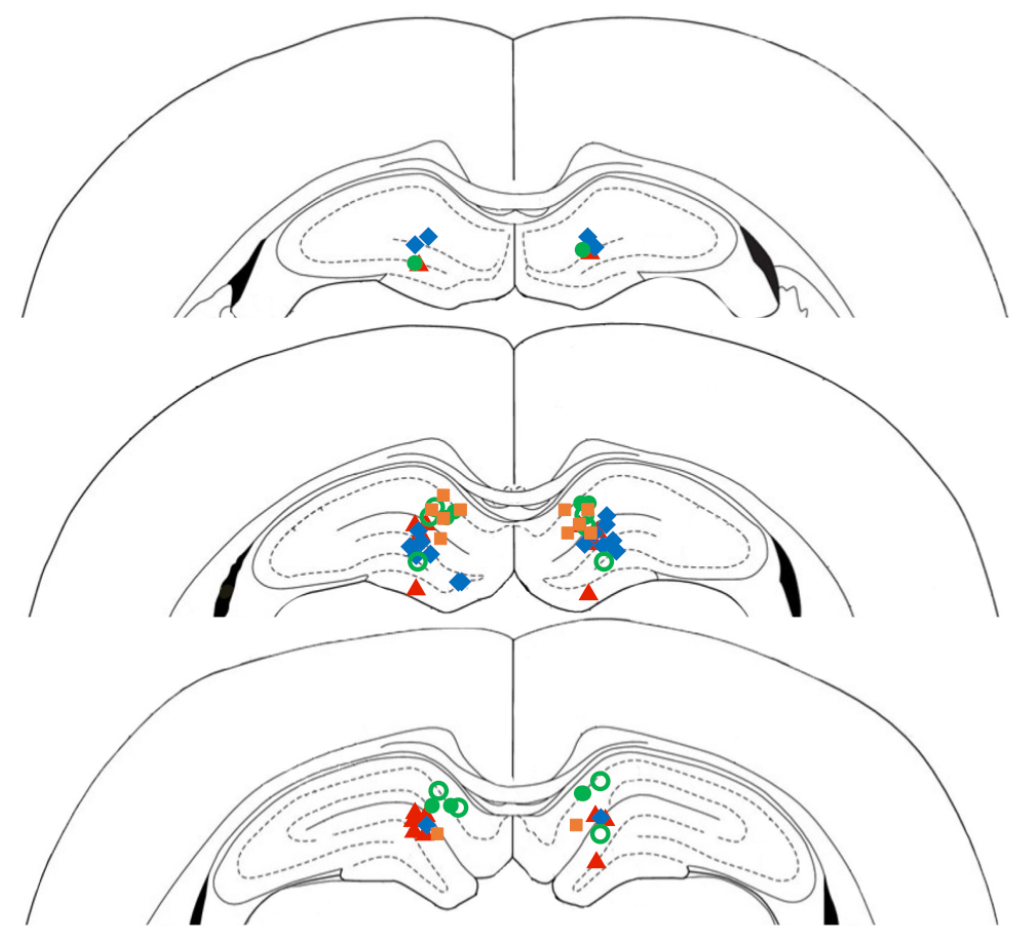

AP from bregma $(\mathrm{mm})$

$-2.75--2.99$

$-3.00--3.49$

$-3.50--3.75$

B

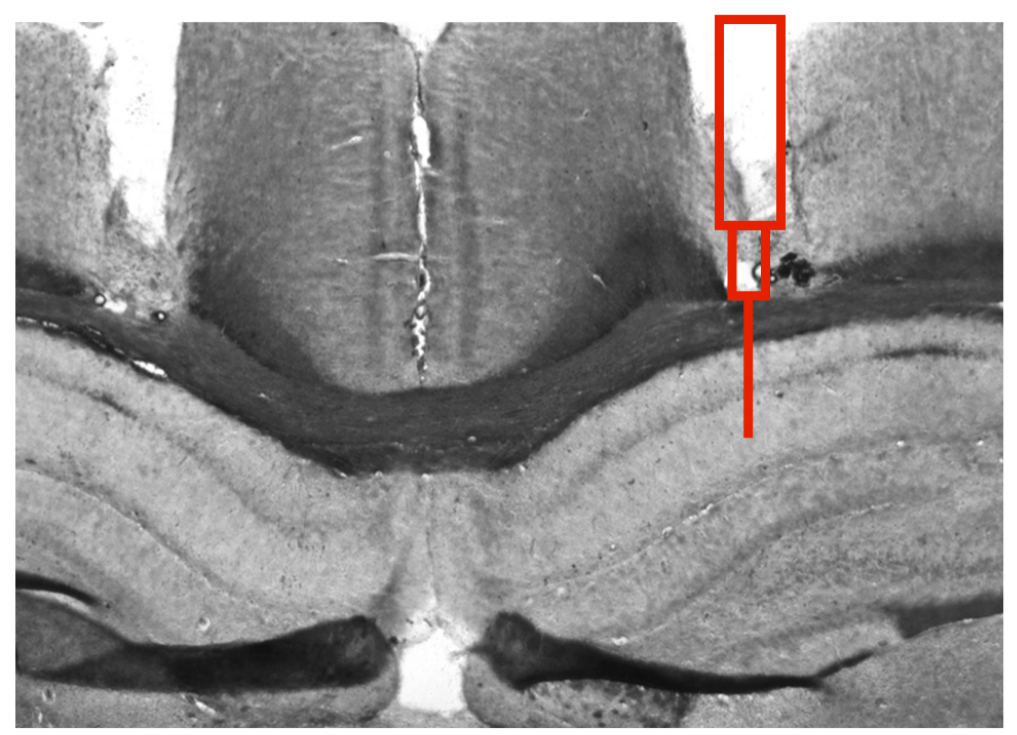




\section{Riordan 35}

Fig 5. Location of infusion cannulae in dorsal hippocampus. A. Dots show final location of bilateral infusion cannulae in PCP, Blk, and PCP+E animals. B. Representative cresylviolet-stained brain section used to verify cannulae placement, with schematic of cannula superimposed over one hemisphere. 
A

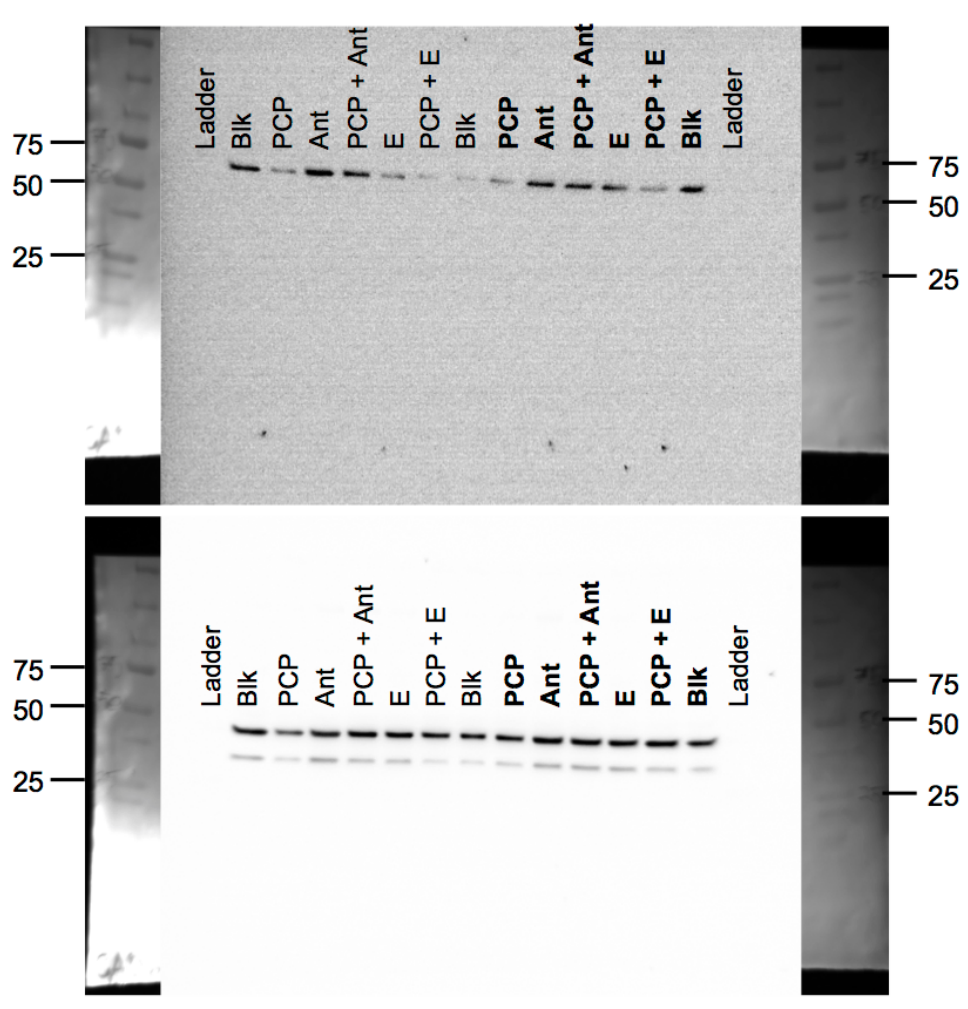

GAD67

$67 \mathrm{kDa}$

$\beta$-actin

$42 \mathrm{kDa}$

B

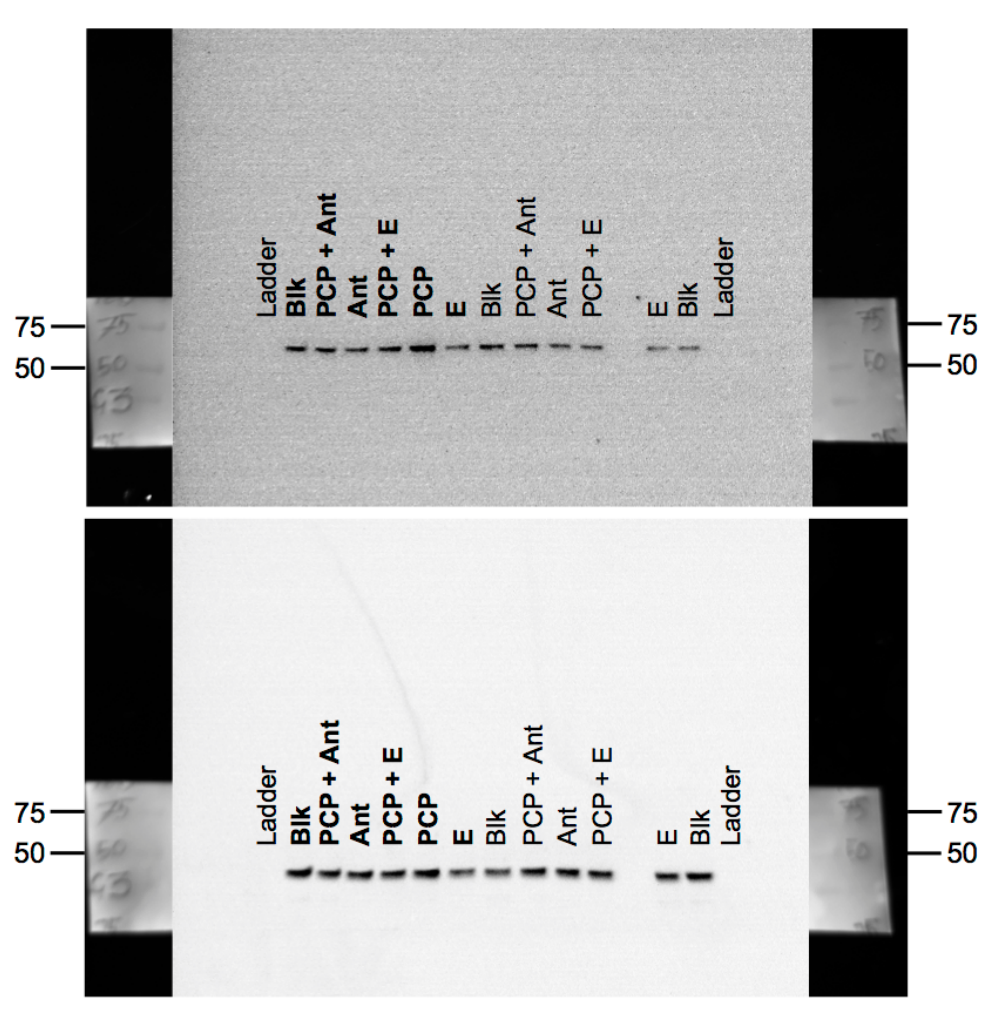

GAD67

$67 \mathrm{kDa}$

$\beta$-actin

$42 \mathrm{kDa}$ 
Riordan 37

Fig S1. Original images of representative western blots from Fig 2. Treatment group is denoted above each band. Wells with bolded labels were rearranged for presentation in Fig 2. Left- and right-most wells of each blot were loaded with molecular-weight marker proteins (Ladder), which also served as negative controls. Blots are flanked by cropped photos of molecular weight markers. All blots appeared at the expected molecular weight for the proteins being analyzed (GAD67: 67kDa; $\beta$-actin: $42 \mathrm{kDa}$ ). A. Original images for hippocampus western blots in Fig 2A. B. Original images for prelimbic cortex western blots in Fig 2B. 
Riordan 38

A

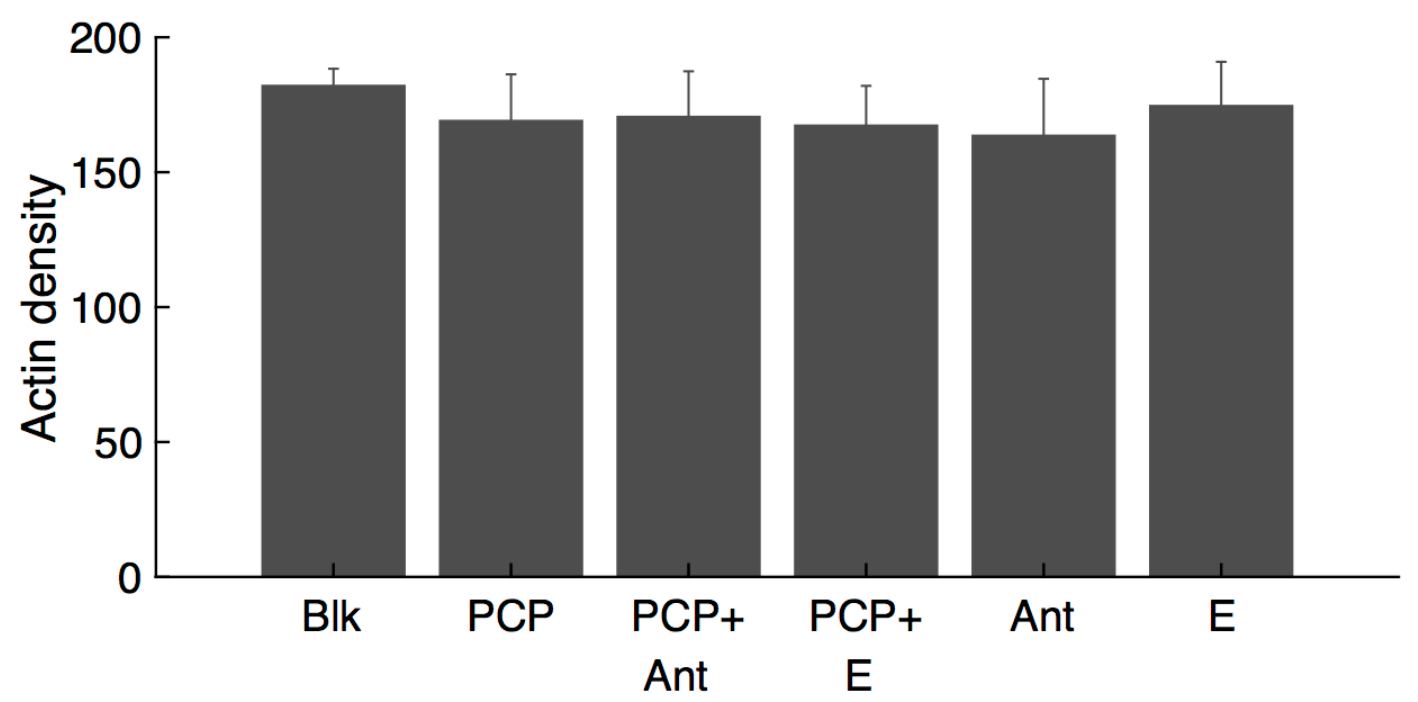

B

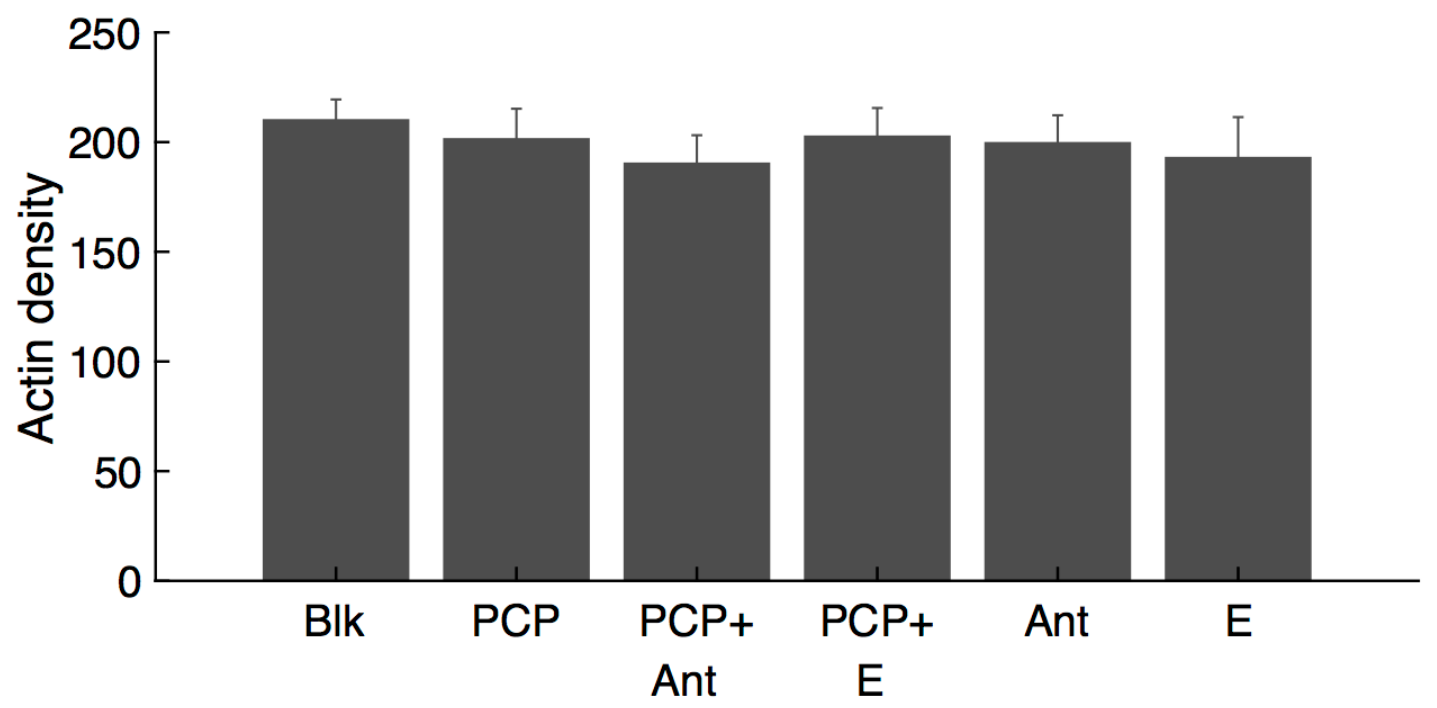


Riordan 39

Fig S2. $\beta$-actin expression, used as a loading control for western blots in Figs 2 and S1, was unaffected by the drug and hormone treatments. That is, one-way ANOVA revealed no significant effect of treatment group on $\beta$-actin densitometry values in the dorsal

hippocampus $\left(A ; F_{5,50}=.28, p=.92\right)$ or prelimbic cortex $\left(B ; F_{5,50}=.17, p=.97\right)$. 
A

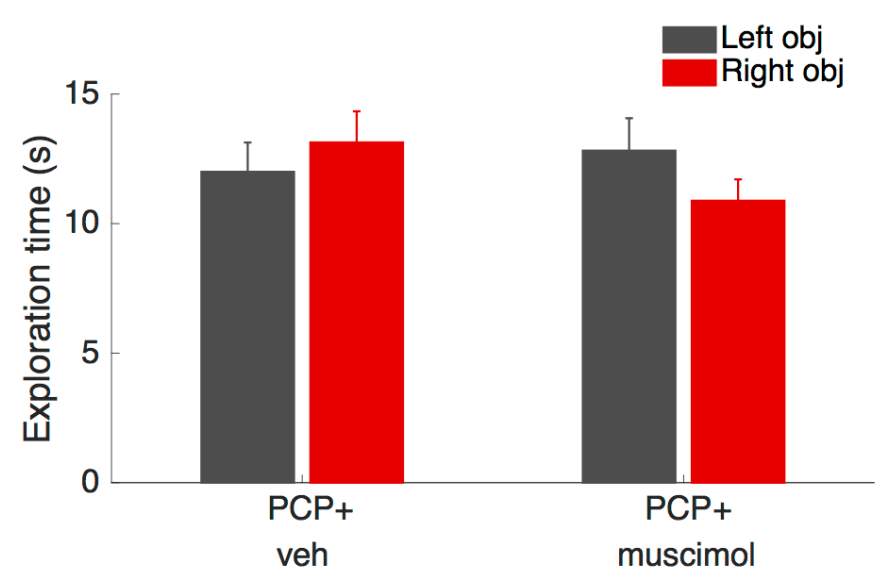

C

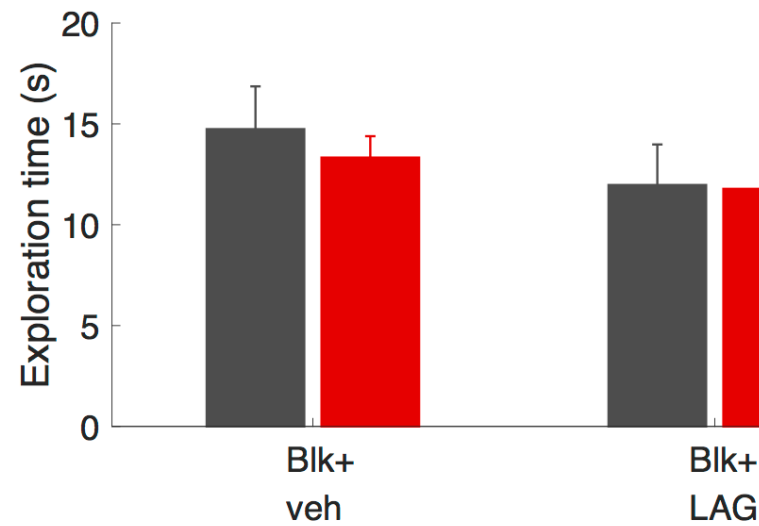

B

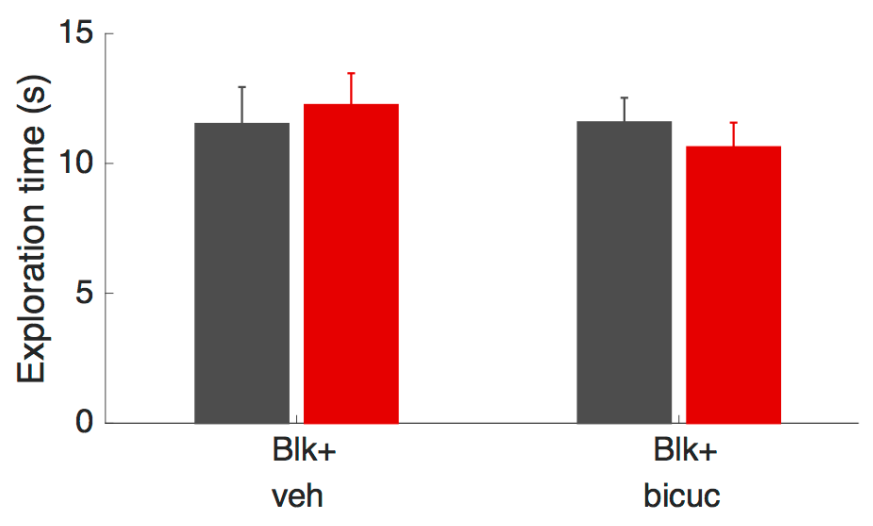

D

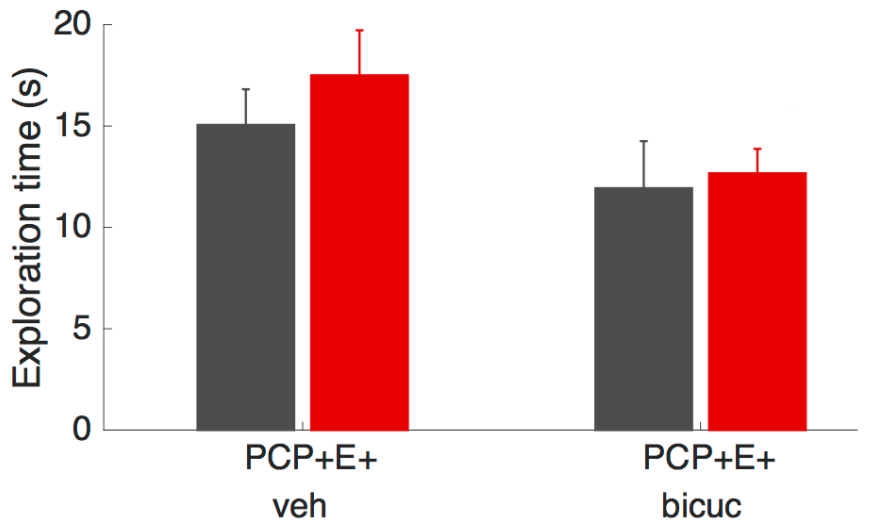

Fig S3. Dorsal hippocampal infusions did not alter object exploration during exposure trial of NORT. No statistically significant differences in total object exploration or left-right object preference were found in any of the experiments. A. PCP+muscimol infusion (Expt. 4A); B. Blk+bicuculline infusion (Expt. 4B); C. Blk+LAG infusion (Expt. 4C); D. PCP+E+bicuculline (Expt. 4D). 


\section{Riordan 41}

A

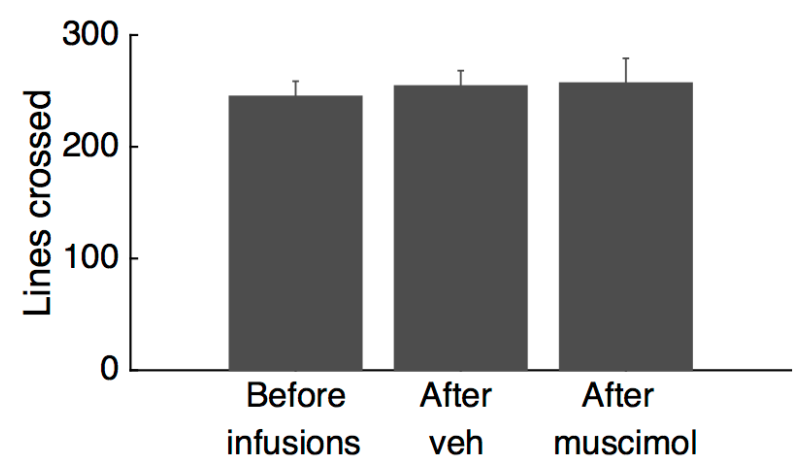

C

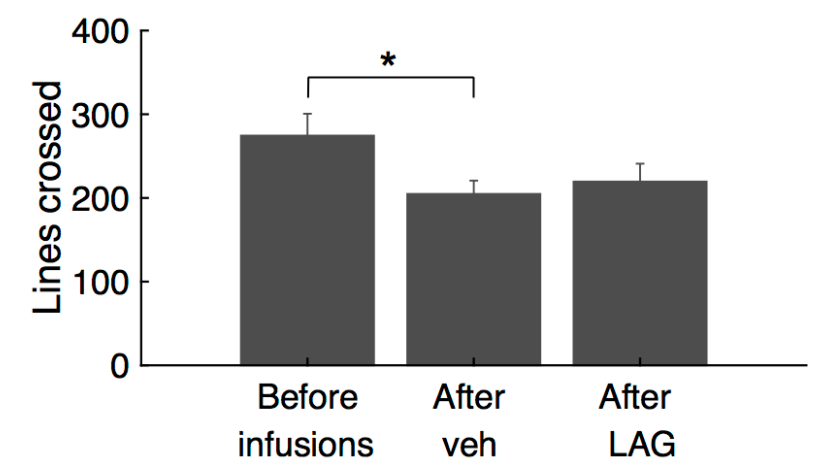

B

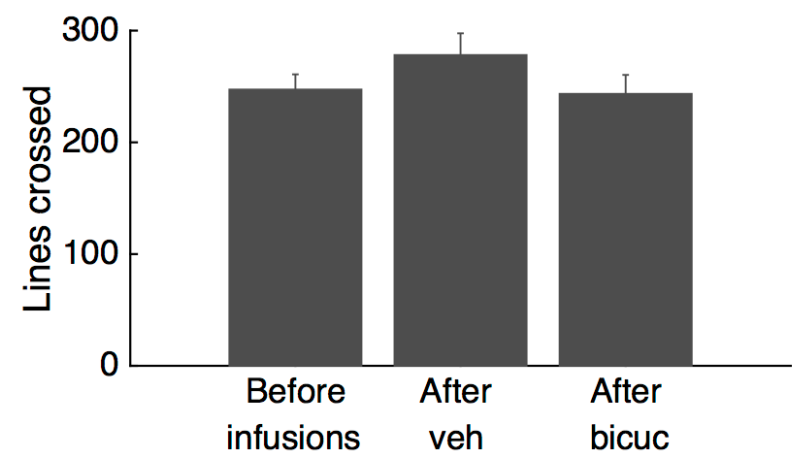

D

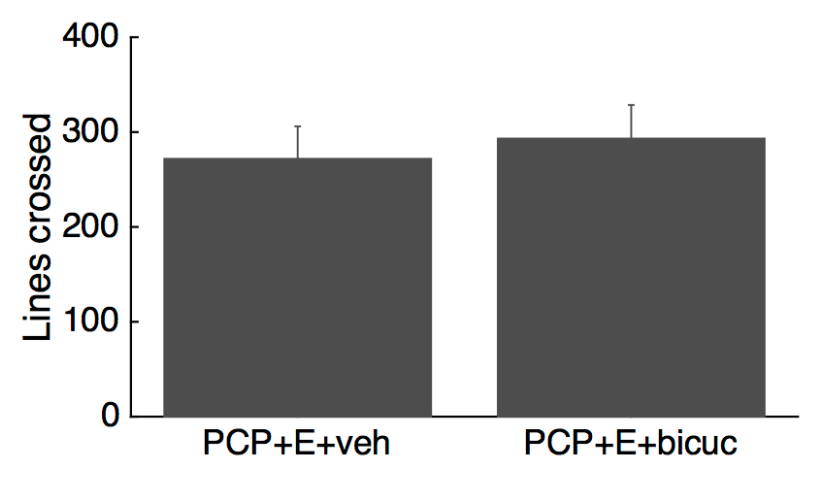

Fig S4. Dorsal hippocampal infusions of GABA antagonist/agonist did not alter the number of lines crossed in locomotion tests. There were no statistically significant differences in lines crossed among infused animals either before or after infusions of drug or vehicle. A. PCP/muscimol infusion experiment. No significant differences. B. Blk/bicuculline infusion expt. No significant differences before vs after drug treatment. The only statistically significant difference was between non-infused and vehicle-infused 
bioRxiv preprint doi: https://doi.org/10.1101/207159; this version posted October 21,2017 . The copyright holder for this preprint (which was not certified by peer review) is the author/funder. All rights reserved. No reuse allowed without permission.

Riordan 42

animals. C. Blk/LAG infusion expt. No significant differences. D. E+PCP/bicuculline infusion expt. No significant differences. 